\title{
How nostalgic brand positioning shapes brand equity: differences between emerging and developed markets
}

\author{
Martin Heinberg ${ }^{1} \cdot$ Constantine S. Katsikeas $^{1}$ - H. Erkan Ozkaya ${ }^{2} \cdot$ Markus Taube $^{3,4}$
}

Received: 14 August 2018 / Accepted: 1 February 2019 / Published online: 26 February 2019

(C) The Author(s) 2019

\begin{abstract}
Extant research has established the effects of nostalgic brand positioning on brand equity, but studies have only examined individual nostalgic brand relationship dimensions separately. Combining these strands, we offer a holistic perspective of the mediating processes and identify contextual and firm-related moderators that affect the individual linkages. We draw on construal level theory and develop a multilevel model in which emotional attachment, brand local iconness, and brand authenticity explain how nostalgic brand positioning creates brand equity. We posit that country differences between emerging and developed markets and brand innovativeness moderate these mediating effects. The results from large consumer samples suggest that emotional attachment and brand local iconness play a weaker role in mediating the connection of nostalgic brand positioning and brand equity in emerging markets. However, this disadvantage in creating brand equity through nostalgic brand positioning in emerging markets can be attenuated with increasing levels of brand innovativeness.
\end{abstract}

Keywords Nostalgic brand positioning $\cdot$ Brand equity $\cdot$ Emerging market $\cdot$ Innovation $\cdot$ Multilevel modeling

Recent nostalgia marketing trends in developed markets have tried to take advantage of current economic and political crises and consumers' propensity to view the past as a happier and less complicated time (Kessous et al. 2015; Muehling and Sprott 2004). Emerging markets have witnessed a similar trend in nostalgia marketing. Nostalgia-themed campaigns and old socialist brands target newly affluent consumers (Clode 2011; Holak et al. 2007). Given nostalgia's pervasiveness in the marketplace, research output has followed suit. It is generally accepted that nostalgia effects can be evoked by

Rajendra Srivastava and V. Kumar served as Special Issue Guest Editors for this article.

Electronic supplementary material The online version of this article (https://doi.org/10.1007/s11747-019-00637-x) contains supplementary material, which is available to authorized users.

Constantine S. Katsikeas

csk@lubs.leeds.ac.uk

Martin Heinberg

m.heinberg@leeds.ac.uk

H. Erkan Ozkaya

ozkaya@cpp.edu

Markus Taube

markus.taube@uni-due.de certain consumer goods in general (Schindler and Holbrook 2003) and by certain brands more specifically (e.g., Smit et al. 2007). Moreover, research has demonstrated that nostalgic positioned brands enjoy enhanced brand equity (Chatzipanagiotou et al. 2016), stronger brand-self connections (Kessous et al. 2015), more favorable product judgments (Gineikiene and Diamantopoulos 2017), and increased purchase intentions and word of mouth (Ford et al. 2018). However, while the general positive impact of nostalgic brand positioning on brand equity and related concepts is evident in
1 Leeds University Business School, Marketing Division, University of Leeds, Maurice Keyworth Building, Leeds LS2 9JT, UK

2 Department of International Business and Marketing, California State Polytechnic University, Pomona, 3801 West Temple Avenue, Building 94-Room 226, Pomona, CA 91768, USA

3 Mercator School of Management, Institute of East Asian Studies, University of Duisburg-Essen, Forsthausweg 2, Building LE-Room 705, 47057 Duisburg, Germany

4 Department of Economics, Nankai University, Tianjin, China 
both research and practice, a comprehensive analysis of how this effect occurs is missing. Moreover, it is unclear if the mechanism differs between developed and emerging markets and if brand innovativeness inhibits or facilitates this process.

We use the term nostalgic brand positioning to refer to a brand positioning strategy that is designed to evoke positive affect in an individual by creating associations with the past. Our focus on nostalgic brand positioning reflects marketing managers' efforts to position the historic roots of a brand to take a prominent role. Research has shown that marketing actions can instill artificial nostalgic feelings in respondents (Braun et al. 2002), and practical examples reveal that even brands with a brief history have been positioned to stress certain historic events that reach back and predate the brand. For example, Moleskine, founded in 1997, markets itself as the heir of the legendary notebooks of such luminary figures as Hemingway, Picasso, and Chatwin (Moleskine 2018), and fashion brand Hollister uses logos and labels related to the year 1922 even though the company was founded 78 years later (BBC 2009). As such, brand managers can shape the role that nostalgic attributes play for a brand. Thus, we deem "nostalgic brand positioning" to be more appropriate than other labels often used in the literature such as "brand nostalgia" (Ford et al. 2018; Fritz et al. 2017), "nostalgic brands" (Kessous et al. 2015), "retro branding" (Brown et al. 2003), or "brand heritage" (Pecot et al. 2018). A nostalgic brand positioning can be shaped across the whole marketing mix. For example, brand managers might introduce special editions related to the past, include the firm's founding date or childhood associations on product packaging, or emphasize the firm's history in advertising campaigns (Aaker 1991; Pecot et al. 2018).

In this article, we draw on a categorizing grid from the psychology literature (e.g., Stephan et al. 2012) that distinguishes nostalgia effects according to social, spatial, and temporal aspects of distance. This categorizing grid is grounded in construal level theory and has received neither conceptual nor empirical attention in the extant marketing literature on nostalgia (Table 1). We propose that empirical research on nostalgic brand relationship dimensions is also associated with social, spatial, and temporal aspects of distance and demonstrate that the individual efforts in this stream of research mainly concentrate on one specific type of distance and lack a more comprehensive view. For example, nostalgic positioned products have been connected to emotional brand attachment (i.e., social distance), brand localness (i.e., spatial distance), or brand authenticity (i.e., temporal distance). Treating these nostalgic brand relationship dimensions separately results in myopic observations of brand-related nostalgia, specifically regarding the conditions under which managers should stress certain relationship dimensions over others.

Our conceptual model draws on nostalgic brand relationship dimensions that reflect social, spatial, and temporal types of distance (1) to examine these different links in parallel and
(2) to investigate if the strength of the respective mediators (a) differs between emerging and developed markets and (b) depends on the level of brand innovativeness contingent on such country effects. We test the conceptual model with a nested dataset that combines 2303 consumer responses with secondary data on the brand innovativeness of 88 real brands.

Our study contributes to the literature in three important ways. First, we integrate the extant brand-related nostalgia literature. We establish that the three links we identify in past research are distinct from one another and are vital means for firms to create brand equity. Addressing this issue is important, as nostalgic brand positioning opens up immense market potential. Disney, for example, has successfully employed the nostalgia factor to broaden its demographic target group and now generates $20 \%-25 \%$ of its total revenue from products for adults. Likewise, when the Nokia brand relaunched, its 10 million mobile phone sales in the first year were backed by the sentimental value of its brand and its nostalgic design (Greene 2009; Spence 2018). A deeper understanding of how the three nostalgic brand relationship dimensions shape brand equity will enable firms to use this strategy more effectively.

Second, despite increasing nostalgia research in developed and emerging markets, differences between these markets are still unknown and unpredictable (Ford et al. 2018). Some researchers have argued that consumers in emerging markets are more optimistic about the future than those in developed markets and are less prone to "believe that the past was better than the present," thus decreasing the potential resonance of nostalgia-driven marketing campaigns (Barry 2016). However, others have reasoned that emerging market consumers feel more pressure in the present than developed market consumers and thus imagine life in the past as "simpler and better." In line with this thinking, emerging market consumers may respond even more favorably to nostalgia marketing than developed market consumers (Euromonitor 2012). Despite these conflicting arguments, to the best of our knowledge, no research has investigated whether developmental differences between these distinct country groups give rise to moderating effects on the various linkages between nostalgic brand positioning and brand equity. Our results reveal that mediation through emotional attachment (reflecting social distance) and mediation through brand local iconness (reflecting spatial distance) of nostalgic brand positioning on brand equity are weaker in emerging markets.

Third, this study helps reconcile discordant findings on the influence of brand innovativeness on the effects of a nostalgic brand positioning. Results from related studies again point in opposite directions. On the one hand, technological innovations may contribute to a resurgence of nostalgic products (Foucart et al. 2018), and updating a historic product to more contemporary standards is key for successful retro branding (Brown et al. 2003). On the other hand, researchers have found an inverse relationship between consumers' predisposition for nostalgia and consumer innovativeness (Steenkamp et al. 1999). 
Table 1 Empirical research on nostalgic brand relationship dimensions

Nostalgic brand relationship dimensions and distance aspects of construal level theory

\begin{tabular}{ll}
\cline { 2 - 2 } Author & Social \\
\hline $\begin{array}{c}\text { Braun-LaTour } \\
\text { et al. (2007) }\end{array}$ & $\begin{array}{l}\text { Emotional attachment to others formed } \\
\text { in childhood influences brand } \\
\text { meanings for adult consumers. } \\
\text { Nostalgic positioned brands can } \\
\text { capitalize on this effect. }\end{array}$
\end{tabular}

Spatial

Temporal Method

Projective technique (qualitative) Nostalgic positioned bra
capitalize on this effect.

Brown et al. (2003)

Dimitriadou et al. (2015)

Ford et al. (2018) Brand attachment, self-brand connection, self-congruence (outcomes of nostalgic brand positioning)

Fournier and Yao Nostalgic memories of relationships (1997) lead to brand attachment.

Fritz et al. (2017)

\section{Gineikiene and Diamantopou- $\operatorname{los}(2017)$}

\begin{tabular}{|c|c|}
\hline $\begin{array}{l}\text { Kessous et al. } \\
\text { (2015) }\end{array}$ & $\begin{array}{l}\text { Brand attachment, self-brand } \\
\text { connections (outcomes of nostalgic } \\
\text { brand positioning) }\end{array}$ \\
\hline $\begin{array}{l}\text { Loveland et al. } \\
\qquad(2010)\end{array}$ & $\begin{array}{l}\text { Consumers' need to belong drives } \\
\text { their preference for nostalgic } \\
\text { products (i.e., nostalgic positioned } \\
\text { products are chosen to satisfy a } \\
\text { social need). }\end{array}$ \\
\hline
\end{tabular}

Leigh et al. (2006)

Pecot et al. (2018)
Rose et al. Brand attachment and commitment as (2016) mediators between brand heritage and purchase intention.
Shields and Brand attitude (outcome of brand Johnson nostalgia) (2016)
Smit et al. (2007) Nostalgia as one way that brands can connect to consumers and become their relationship partners.

Thelen et al. (2006)

\section{Nostalgia leads to local product preference.}
Nostalgia counteracts animosity connected to past events and enhances product judgments (implicit spatial argument connected to perceived localness of brands).

Retro brands balance the past and future. A successful balance creates authenticity, which is key for a retro brand's meaning.

Netnography (ethnography in the web)

Experiment

Brand trust (outcome of nostalgic Survey brand positioning as it develops over time)

Qualitative

Brand nostalgia leads to brand authenticity.

Survey

Survey

Survey

Experiment

Brand heritage contributes to perceived authenticity of an object.

Brand consistency and brand clarity mediate relationship between brand heritage and willingness to pay a premium (i.e., brand equity).

Ethnography

Survey

Survey

Experiment

Scale development

Nostalgia is an antecedent to consumer ethnocentrism (i.e., moral inclination to prefer local products) in emerging markets.
Moreover, consumers do not appreciate large changes to a brand they have nostalgic feelings for (Shields and Johnson 2016). The latter set of findings suggests that innovations might hurt the success of nostalgic positioned brands and, as such, appear to contradict the former stream of findings. We demonstrate that the influence of brand innovativeness is contingent on context. 
In developed markets, brand innovativeness does not translate into a stronger link between nostalgic brand positioning and brand equity. However, brand innovativeness helps attenuate the disadvantages that emerging markets show in creating brand equity through nostalgic brand positioning. Disregarding such significant differences between emerging and developed markets will hurt a firm's competitive edge (Sheth 2011).

Next, we discuss construal level theory as the overarching framework for our research and build a model to depict the process of how nostalgic brand positioning creates brand equity. We then formulate hypotheses regarding the effects of country setting and brand innovativeness. Subsequently, we explain our methodology, present the results, and discuss the theoretical and managerial implications of our findings.

\section{Theoretical framework}

We approach nostalgia from the standpoint of construal level theory. Construal level theory is concerned with different forms of psychic distance (e.g., Ding and Keh 2017; Liberman and Trope 2008; Roehm and Roehm 2011). A key tenet of this theory is that distal stimuli are mentally construed because they cannot be experienced directly. The mental representations of distal events are thus relatively more abstract, coherent, and super-ordinate (i.e., a higher-level construal) than the more concrete mental representations of proximal events (i.e., a lower-level construal). The three main forms of psychic distance discussed in construal level theory are social, spatial, and temporal (Stephan et al. 2012; Trope and Liberman 2010). The human brain organizes information related to social, spatial, and temporal distances in a similar manner (Parkinson et al. 2014). Moreover, work in social psychology has shown that social, spatial, and temporal distances are interlinked (Liberman and Trope 2008). We exclude other notions of psychic distance mentioned in the broader construal level literature, such as culture or probability (Trope et al. 2007), because they have not been the focus of attention in nostalgia-related research (Stephan et al. 2012). The extant psychology literature on nostalgia has related the three aspects of distance to nostalgic relationship dimensions pertaining to social (e.g., social connectedness), spatial (e.g., thinking of certain places or events), and temporal (e.g., yearning for old times/childhood) elements (e.g., Stephan et al. 2012; Wildschut et al. 2006, 2010). Following this line of reasoning also offers a grid for understanding the effects of nostalgic brand positioning. Based on fieldwork interviews and supported by the literature, we identify three nostalgic brand relationship dimensions - emotional attachment, brand local iconness, and brand authenticity - that are fundamental dimensions of individuals' relationships with nostalgic brands. These three dimensions, respectively, reflect the social, spatial, and temporal aspects of distance in construal level theory and together constitute the mechanism that allows nostalgic brand positioning to facilitate enhanced brand equity.

Emotional attachment, which refers to the affective connection consumers have formed with brands, corresponds to the social distance aspect of construal level theory. This understanding reflects the notion that consumers' emotional attachment to brands mimics social attachment. For example, nostalgia has been identified as one type of consumer-brand relationship (Fournier and Yao 1997; Smit et al. 2007), and it has been argued that nostalgic brands serve as substitutes for social relationships (Loveland et al. 2010). As such, several researchers have identified emotional attachment to brands or related constructs to be a consequence of nostalgia. For example, nostalgic memories connected with car brands create emotional safety (Braun-LaTour et al. 2007), and nostalgic brands enjoy enhanced brand attitudes, brand attachment, and self-brand connections compared with non-nostalgic brands (Kessous et al. 2015; Rose et al. 2016; Shields and Johnson 2016). While other constructs have been employed to capture the social distance aspect (e.g., self-brand connection, self-congruence, commitment; see Ford et al. 2018; Kessous et al. 2015; Rose et al. 2016), previous research has identified these constructs as antecedents, factors, or even "cousin constructs" of brand attachment (e.g., Coulter et al. 2003; Malär et al. 2011; Park et al. 2010). We select the construct of emotional brand attachment to represent the social distance aspect because it encompasses related constructs, has been recurrently used in nostalgic brand positioning studies, and it is solidly established within the branding and brand management literature (Table 1).

The spatial distance aspect of construal level theory is reflected in the nostalgic brand relationship dimension of brand local iconness, which addresses perceptions of localness or feelings toward one's home evoked by brands. For example, researchers have discovered that nostalgic consumers tend to prefer local products (Dimitriadou et al. 2015). Moreover, a consumer's predisposition for nostalgia is related to his or her ethnocentric tendencies (Thelen et al. 2006). As such, a brand that creates associations with the past may be successful because it conveys the perceived local iconness of a brand. Perceived local iconness is the key construct encapsulating the symbolic value consumers assign to a brand's local origin in the brand management literature (Steenkamp et al. 2003) and therefore effectively captures the spatial distance aspect of construal level theory.

Finally, the temporal distance aspect of construal level theory is reflected in extant findings that nostalgic positioned brands are successful because consumers come to perceive them as authentic or "true" over time (Brown et al. 2003; Fritz et al. 2017; Leigh et al. 2006). The notion of authenticity as a connection with the past has been explained using two different logics. One logic posits that nostalgic memories are both rocky and rosy rather than merely positive, and therefore 
they are perceived as more authentic (Stephan et al. 2012). Another logic is based on a signaling perspective and argues that consistency and clarity in brand history create feelings of authenticity and, in turn, trust (Ford et al. 2018; Napoli et al. 2014; Pecot et al. 2018). These ideas of genuineness and consistency over time are both central elements of brand authenticity (e.g., Fritz et al. 2017) and they also correspond to the temporal aspects of construal level theory (Stephan et al. 2012). Moreover, brand authenticity has been used recurrently by previous nostalgic brand positioning studies as an outcome of emphasizing a brand's past and heritage (Brown et al. 2003). As such, brand authenticity is a suitable nostalgic brand relationship dimension that reflects temporal distance (Table 1).

In addition to providing a categorizing grid for the effects of nostalgic brand positioning, construal level theory can also help understand the unique construal pattern of nostalgia. This pattern includes a higher-level (i.e., abstract) construal regarding the past and a lower-level (i.e., concrete) construal that entails the relevance of a past event to the present (Stephan et al. 2012). Memories of past events or places are preserved, and often idealized, over time, leading to a more abstract psychological perspective. In addition, concrete emotions and interactions with others often become the key facilitator for nostalgia when connecting the past to the present (Wildschut et al. 2006). Importantly, we argue that the interplay between lower-level and higher-level construal is present in all nostalgic brand relationship dimensions.

This understanding of nostalgia yields insights into potential factors that could strengthen or weaken the linkage between nostalgic brand positioning and brand equity and, thus, facilitate or inhibit the success of this positioning strategy. Such factors may be connected to higher-level construal (e.g., a blurring of the past), lower-level construal (e.g., an obstruction of the emotional transfer), or an interplay between the two (e.g., a drastic change of brand image over time).

\section{Development of hypotheses}

Before we discuss the mediators, a brief elaboration on our choice of brand equity as the dependent variable is warranted. Brand equity is widely understood as the "value added to a product by its brand name" (Yoo et al. 2000, p. 195). In other words, it provides "meaning" to a product for a consumer beyond actual product features (Park and Srinivasan 1994) and is therefore a good fit for investigations of brand positioning efforts (Keller 1993). As such, the link between nostalgic brand positioning and brand equity has also been tested in the literature (e.g., Boyle and Magnusson 2007; Chatzipanagiotou et al. 2016). In addition to fit at the theoretical level, brand equity is a key measure of managerial interest because it reduces costs (Rego et al. 2009), allows for a price premium
(Ailawadi et al. 2003), and increases company profits (Katsikeas et al. 2016).

Drawing on the foregoing discussion of the three linkages that explain how nostalgic brand positioning leads to brand equity, we now consider the three nostalgic brand relationship dimensions - the mediators of emotional attachment, brand local iconness, and brand authenticity, which reflect the social, spatial, and temporal distance aspects of construal level theory, respectively.

It has been shown that emotional attachments to brands mirror social attachments to other people (Fournier 1998). Moreover, emotional brand attachment has been identified as a key consequence of nostalgic brand positioning (Ford et al. 2018). Therefore, emotional attachment to a brand is a fundamental nostalgic brand relationship dimension, representing the social distance aspect of construal level theory. Emotional attachment to a brand is related to meaningful memories a person associates with the brand (Ball and Tasaki 1992). Logically, memories require time to accumulate. As such, it has been argued that emotional attachment follows only after multiple interactions (Thomson et al. 2005). It also stands to reason that older brands have had more time to shape such memories. For example, the main explanatory variable for why older consumers choose older brands is their emotional brand attachment (Lambert-Pandraud and Laurent 2010). In turn, emotional attachment has been shown to strengthen brand equity (e.g., Park et al. 2010); thus, we argue that emotional attachment is a mediator of the nostalgic brand positioning-brand equity relationship.

As for the spatial distance aspect, the notion of nostalgia goes back to Hofer (1934), who described an illness caused by the separation from one's home (i.e., a homesickness-related depression) and crafted the term nostalgia from the two Greek words nostos ("return to the native land") and algos ("pain"). In other words, nostalgia is a pain caused by the distance from one's home. While the understanding of nostalgia has shifted from pain to a more bittersweet, or even positive, emotion (Holbrook 1993), the notion of home is still "considered a key element in reference to nostalgia" (Muehling et al. 2014, p. 74). Thus, brand local iconness is the second crucial nostalgic brand relationship dimension, reflecting spatial distance aspects. It has been argued that a person's consumption environment in the past tended to be local (Steenkamp and De Jong 2010). It has also been shown that nostalgia leads to increased preferences for domestic products (Dimitriadou et al. 2015). In addition, the local iconness of a brand increases consumers' purchase intentions (Steenkamp et al. 2003). As such, we argue that nostalgic positioned brands may profit from a favorable local image, which in turn enhances brand equity.

Brand authenticity is a third fundamental nostalgic brand relationship dimension and reflects the temporal distance aspect. The past tends to be viewed as "pristine and naturalistic" 
in nostalgic memories (Leigh et al. 2006, p. 486), whereas the present is often connected to the idea of "inauthenticity" (from fake news to fake brands). Authentic brands manage to become "true" over time. For example, psychological research has shown that nostalgic memories are perceived as more authentic than positive or ordinary memories because of their bittersweet affective nature (Stephan et al. 2012). Similarly, nostalgic positioned brands are often connected with such ambivalences, which explains their authenticity (Brown et al. 2003), and thus can help drive purchase intentions (Fritz et al. 2017).

In accordance with our discussion of the three nostalgic brand relationship dimensions, we hypothesize the following:

H1: The nostalgic brand positioning-brand equity relationship is mediated by (a) emotional attachment, (b) brand local iconness, and (c) brand authenticity.

Figure 1 depicts these hypothesized relationships. Subsequently, we argue that the first two hypothesized mediations are potentially moderated by (1) the country setting, (2) brand innovativeness, and (3) an interaction between both variables. With regard to country setting, we take developed markets as the baseline condition because the majority of research has been conducted in developed markets, and then we compare emerging markets to this baseline scenario. Regarding the mediating role of brand authenticity (i.e., the nostalgic brand relationship dimension addressing the temporal distance aspect of construal level theory), we do not hypothesize moderation effects because there is no theory-based rationale to support an expectation of differences between emerging and developed markets. While it may be possible to formulate a hypothesis based on cultural differences with regard to time (e.g., long-term orientation), we do not view differences between emerging and developed markets as mainly culture based (Eisend et al. 2017). In addition, it has been argued that nostalgia is relatively stable across cultures (Hepper et al. 2014). Similar to the country setting, there is also no compelling theoretical logic for a moderating effect of brand innovativeness on the mediating role of brand authenticity. The literature has not developed theoretical guidance, but has produced mixed findings regarding the effect (Beverland 2005; Beverland et al. 2010; Choi et al. 2015). A possible reason is that temporal distance appears to be related to the type of innovation but not necessarily to brand innovativeness (Castaño et al. 2008; Ziamou and Veryzer 2005). Next, we discuss potential moderating effects on the mediating link via emotional attachment and then on the link via brand local iconness.

According to construal level theory, the success of nostalgic brand positioning relies on abstract memories from a past event in connection with concrete, often emotional elements that link the past to the present (Stephan et al. 2012; Wildschut et al. 2010). We posit that this relationship is fragile and that a factor such as "noise," induced by consumers' propensity to trade up continually or by multiple competing brands in the market might impede the effects of nostalgic brand positioning. For example, Pieters and Bijmolt (1997) have shown that the number of competing advertisements decreases advertising effectiveness.

The competition among brands in emerging markets is more intense than it is in developed markets, especially over the last few decades (Glen et al. 2003). Market growth in emerging markets naturally attracts competitors, whereas developed markets are more consolidated and have long established barriers of entry. Competition in emerging markets is further enhanced by domestic brands, which try

Fig. 1 Conceptual model

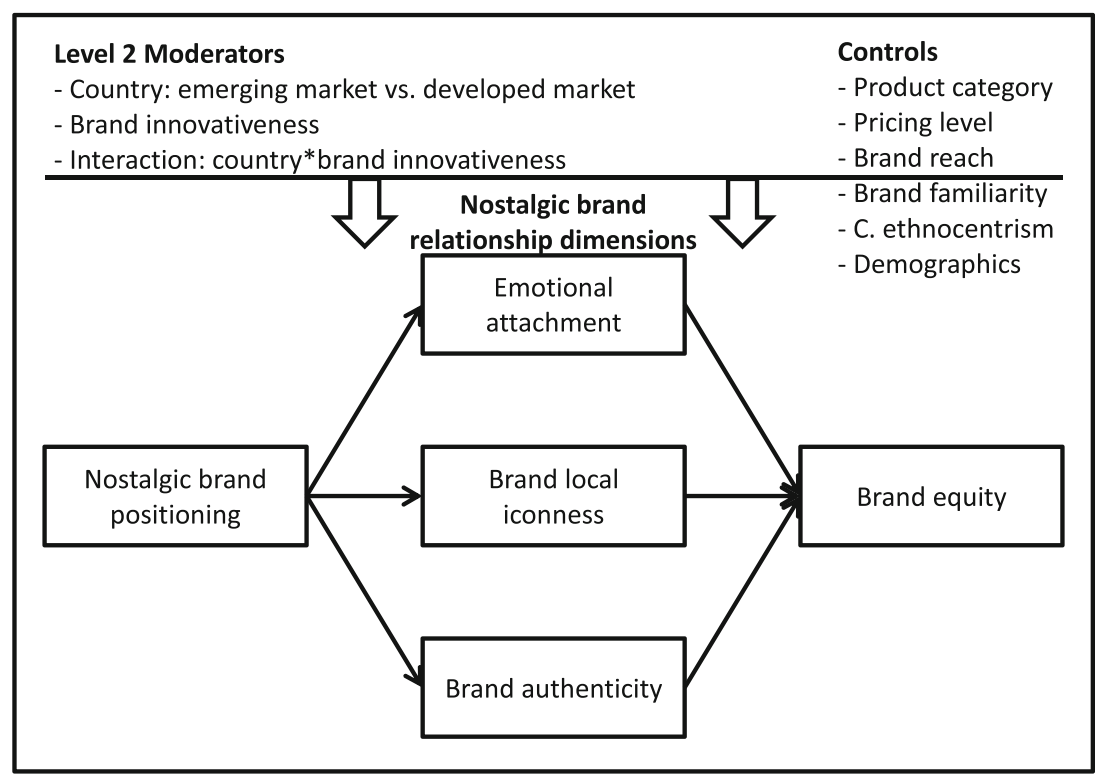


to defend their home turf. For example, The Economist (2014) reports that there are two to three times more brands on the shelves in emerging markets. The presence of such fierce competition implies that establishing an emotional connection, or attachment, to a brand might be more difficult. In addition, increasing disposable income in emerging markets has resulted in a pattern of trading up by consumers over a wide range of product categories (Anestis et al. 2008; Cavusgil et al. 2018). Consumers are continually raising their expectations and are slowly climbing up the premium ladder. An important consequence of this behavior is that their consideration set is constantly evolving, leading to lower levels of emotional attachment compared with developed market consumers. Indeed, it has been found that the level of consumer loyalty is lower in emerging markets (Atsmon et al. 2010; Liu et al. 2016). Apart from certain specific categories, such as baby products, emerging market consumers tend to have a repertoire of several brands they purchase on an alternating basis rather than showing attachment to one particular brand. A recent study found that even the leading brands in an emerging market lose $30 \%-60 \%$ of their shopper base each year (Lannes and Booker 2013). Another sign of lower emotional connections with brands among emerging market consumers is their propensity to make their final purchase decision while in stores, compared with developed market consumers, who tend to know which brands they intend to purchase before entering a store (Atsmon et al. 2012). In summary, we argue that the intense competition among brands and consumers' propensity to continuously trade up create an environment that impedes the ability of nostalgic brand positioning to create brand equity via emotional attachment in emerging markets. ${ }^{1}$

According to the construal level theory approach to nostalgia (Stephan et al. 2012), brand innovativeness could have two contrary effects on the emotional attachment mediator. On the one hand, it could be argued that brand innovativeness increases psychic distance with respect to the brand. More innovations could blur the past memory of a brand, resulting in only a vague memory of it. On the other hand, it could be argued that brand innovativeness helps a brand stay relevant, thus increasing the present connection a consumer experiences with a brand.

The literature has produced results supporting both arguments. Regarding the former, Shields and Johnson (2016) find that consumers do not like large changes to brands they have nostalgic feelings for. Regarding the latter, it is widely accepted that successful innovations help improve consumers' brand

\footnotetext{
${ }^{1}$ One might raise the point that superior marketing characteristics (e.g., attractive pricing and product availability) are antecedents to emotional attachment (Grisaffe and Nguyen 2011) and that lower price points and potentially greater availability in emerging markets lead to stronger emotional attachment of consumers to brands. However, in reality, such lower price points are relativized by lower incomes, and availability in emerging markets is inhibited by infrastructure constraints (Sheth 2011).
}

perceptions, strengthen brand attitudes, and enhance brand associations (Brexendorf et al. 2015). It has also been argued that innovations can revitalize a brand (Beverland et al. 2010). We adopt the latter argument because of the well-recognized importance of brand innovativeness for the formation of brand equity (e.g., Aaker 2012) and the expectation that such a logic would also apply to brands positioned as nostalgic. Therefore, we argue that brand innovativeness enhances consumers' emotional attachment to a brand. Consider, for example, Brown et al.'s (2003) discussion of the success of retro branding, which is tied to the paradox of tradition versus new technology.

Moreover, we predict an additional interaction between the country setting and brand innovativeness. As we have discussed, the level of competition in emerging markets has increased considerably over the past few years, and growth in disposable income has led to continuously evolving consideration sets for consumers. Both factors impede consumers from forming emotional attachments to brands. However, we posit that more innovative brands get more attention than other brands in their category and thus might be less prone to the negative effects of overcrowding, excessive competition, and low loyalty present in emerging markets. Research has also suggested that brand innovations may contribute to brand awareness (Brexendorf et al. 2015). Therefore, we hypothesize that the negative emerging market effect of mediation through emotional attachment is attenuated by higher levels of brand innovativeness.

\section{H2: The mediation effect through emotional attachment is moderated by}

(a) country setting, such that there is a weaker link in emerging markets than in developed markets;

(b) brand innovativeness, such that there is positive moderation in developed markets; and

(c) the interaction between (a) and (b), such that the weaker link in emerging markets is attenuated by increasing levels of brand innovativeness.

The mediation hypothesis regarding brand local iconness (which addresses the spatial distance aspect of construal level theory) is based on the argument that a nostalgic brand positioning enriches the brand's sense of "home." We posit that this mediation effect is weaker in emerging markets because the connection to localness will evoke fewer positive attributes for emerging market consumers than for developed market consumers (Özsomer 2012; Steenkamp et al. 2003). In other words, it is more difficult to establish an emotional hook based on local iconness in emerging markets. While, at present, we are witnessing the rapid rise of emerging markets (e.g., increased political and economic power, local brands entering the global stage), the childhood of today's emerging market 
consumers is often associated with local poverty and hardship. Even the millennial generation grew up in an environment in which foreign brands stood for superior quality and prestige (Batra et al. 2000; Hung et al. 2007). Emerging market consumers have seen many of their domestic products replaced by imports and global brands (Thelen et al. 2006), and therefore they tend to prefer foreign brands to local ones (Sharma 2011). When transferring this notion to the understanding of nostalgia in accordance with the tenets of construal level theory, one might argue that the connection of the past to the present does not facilitate the emotional transfer that is necessary. As such, local brand attributes in emerging markets are endowed with a weaker link to brand equity. Therefore, we posit that although nostalgic brand positioning may increase brand local iconness in emerging markets (Holak et al. 2007), such an effect would be offset by a less favorable view of local brand attributes in emerging markets. If local iconic status is worth less in emerging markets, any returns in the form of enhanced brand equity are likely to be less than they are in developed markets.

With regard to the effect of brand innovativeness on mediation via brand local iconness, construal level theory suggests that the success of nostalgic brand positioning depends on an interplay of higher-level and lower-level construal (Stephan et al. 2012). We posit that brand innovativeness decreases mediation through brand local iconness in developed markets because innovations tend to increase distance with respect to the concept of "home" encapsulated in brands; in other words, innovative brands evolve away from their local past, and this change of image disturbs the interplay of higher-level and lower-level construal. The reason is that global competition often serves as a trigger for innovations. At the same time, innovations are costly, which is why innovations tend to be developed to target multiple countries (Harvey and Griffith 2007). As such, it may be argued that globalization drives the innovation of more global products (Steenkamp and De Jong 2010). In turn, the enhanced globalness of a product may decrease the effects of local iconness (Heinberg et al. 2017). In line with this reasoning, Özsomer (2012, p. 76) argues that the globalization of a local brand is viewed as a "loss of commitment to home" by developed country consumers. As such, we hypothesize that brand innovativeness decreases mediation through brand local iconness in developed markets.

We argue that this influence of brand innovativeness has a different effect on mediation through local iconness in emerging markets compared with developed markets. The fundamental rationale is that emerging market consumers take pride in the global success of their local brands even if this involves a loss of local iconic image (Özsomer 2012). This argument appears particularly relevant to innovations, as brand innovations embody the growing strength of emerging market economies. Thus, possible cultural incompatibility arguments (Heinberg et al. 2017) may be less pertinent in this case, and gaining a competitive edge among global brands through innovation should attenuate the negative effect of the emerging market setting. In other words, emerging market consumers feel greater pride and self-relevance for innovative local iconic brands than for non-innovative local iconic brands, which enables the emotional transfer that is necessary and strengthens the otherwise weak brand local iconnessbrand equity link. Therefore, we hypothesize the following:

H3: The mediation effect through brand local iconness is moderated by:

(a) country setting, such that there is a weaker link in emerging markets than in developed markets;

(b) brand innovativeness, such that there is negative moderation in developed markets; and

(c) the interaction between (a) and (b), such that the weaker link in emerging markets is attenuated with increasing levels of brand innovativeness.

\section{Empirical study}

We selected China and Japan to represent emerging and developed markets, respectively. Both are major economies, ranking second and third in the world according to gross domestic product. More importantly, the two countries are culturally close, especially regarding the dimension of long-term orientation (Hofstede and Minkov 2010; China: 87; Japan: 88). This dimension captures the future and past orientations of a society and, as such, might contribute to a potential cultural explanation of nostalgia effects (Hepper et al. 2014). By selecting China and Japan, we eliminate such a confounding influence and aim to establish differences between emerging and developed markets beyond a cultural explanation.

We use multilevel moderated mediation analysis to test our hypotheses (Hox 2010). This technique allows for the inclusion of a large number of real brands, ensuring the external validity of our study. In addition, we account for the nested data structure and therefore avoid the underestimation of standard errors, leading to a decrease in the probability of Type 1 errors (Ozkaya et al. 2013). This approach also enables us to tap different data sources for level 1 (i.e., consumer) and level 2 (i.e., brand) variables, thus eliminating common method bias for between-level results.

We selected fast-moving consumer goods (FMCGs) as an appropriate category for this research because they comprise a wide range of products and have been used extensively in previous studies. Other product categories employed in prior nostalgia research are big-ticket items (e.g., automobiles) and thus were not affordable to emerging market consumers or their families, especially during their childhood (when many nostalgic connections are formed; see Holbrook 1993). In 
addition, FMCGs are of practical relevance as they combine about a quarter of all advertising spending globally (Nielsen 2013). Moreover, they have the advantage of including numerous brands that consumers are familiar with, many of which are household names (Heinberg et al. 2016). As such, there is an extensive pool of brands for our selection process. We excluded brands from categories related to infants, pets, and alcohol due to their specificity to particular consumer segments. We selected brands for the empirical study using a three-step process. Because our aim was not to compare differences in consumer perceptions of specific brands, we selected brands in each market separately. Relying on secondary data from GlobalData (a product launch analytics database), we selected brands with at least one innovation over the last two years. Excluding brands without any innovation during this time span avoids a right-skewed distribution of outdated or stagnating brands and results in a more normally distributed brand innovativeness variable. The GlobalData database has been used widely in the marketing field (e.g., Lamey et al. 2012; Sorescu and Spanjol 2008) and was available for both China and Japan.

Next, we conducted a pilot study ( $n=100$, China; $n=98$, Japan) to ensure consumer familiarity with the different brands. Finally, we selected 40 brands for the developed market and 48 for the emerging market (see Web Appendix 1 for a list of brands, including their country of origin, year of market entry, and brand reach). Importantly, we did not select Japanese brands for the Chinese sample (and vice versa) to avoid any effects of potential animosity between the two countries (Klein et al. 1998). The selected brands show a wide range in terms of their year of market entry (emerging: 19122017; developed: 1919-2012), thus allowing for differences in the development of nostalgic feelings. Both brand selections have a similar number of minimum (emerging $=1$; developed $=1)$ and maximum $(17 ; 19)$ innovations per brand, as well as a similar mean $(5.3 ; 4.6 ; p>.3)$. In other words, the number of innovations is not dependent on the country setting.

We selected respondents for the main study using quota sampling based on age, gender, and brand from an online panel from a reputable market research agency. We restricted the sample to age groups between 18 and 55 years to ensure internet literacy and to avoid the trap of generational differences in emerging markets. Older consumers in emerging markets have enjoyed fewer benefits from economic reforms and often display different shopping behaviors, frequenting wet markets instead of modern shopping formats (Heinberg et al. 2016). Overall, we collected 1253 valid respondents in China and 1050 in Japan (approximately 26 per brand), and our samples are representative in terms of gender and respective age groups in each country (Table 2). Each respondent was only surveyed about one brand, which was assigned using a two-stage random process. First, we randomly selected 10 brands from the overall sample of brands in each country and
Table 2 Country and respondent demographics

\begin{tabular}{|c|c|c|c|c|}
\hline \multirow[b]{2}{*}{ Category } & \multicolumn{2}{|c|}{ Emerging market (China) } & \multicolumn{2}{|c|}{ Developed market (Japan) } \\
\hline & $\begin{array}{l}\text { Country } \\
\text { population }\end{array}$ & Respondents & $\begin{array}{l}\text { Country } \\
\text { population }\end{array}$ & Respondents \\
\hline$\%$ female & $48.8 \%$ & $48.8 \%$ & $51.3 \%$ & $50.8 \%$ \\
\hline \multicolumn{5}{|c|}{ Age groups } \\
\hline $18-24$ & $14.3 \%$ & $15.4 \%$ & $12.9 \%$ & $11.4 \%$ \\
\hline $25-34$ & $27.8 \%$ & $29.0 \%$ & $23.5 \%$ & $23.9 \%$ \\
\hline $35-44$ & $25.2 \%$ & $25.7 \%$ & $30.5 \%$ & $31.2 \%$ \\
\hline $45-55$ & $32.7 \%$ & $29.9 \%$ & $33.1 \%$ & $33.5 \%$ \\
\hline
\end{tabular}

displayed the list, including logo and brand name in the respective language, at the onset of each study. This list always included one phony brand, which we created to eliminate consumers who would not exercise the necessary care when responding to our survey. We then checked the respondents' familiarity with each brand using a seven-point Likert scale. Second, we eliminated all respondents who did not clearly indicate their non-familiarity with the phony brand and then randomly selected the brand for the subsequent survey of the specific respondent from the list of brands the respondent was at least somewhat familiar with.

\section{Measurement}

Measurement of the level 1 variables builds on established research (Table 3 ). We relied on reasonably compact scales with three or four items per construct to ensure respondents' attention to the survey. While three items is generally viewed as the minimum for a reliable measurement, we acknowledge that measurement scales with more items might offer advantages in terms of enhanced scale reliability and increased variability (Diamantopoulos et al. 2012). After drafting the questionnaire, we depended on five marketing academics as expert judges to establish content validity. Each rated the relevance of the respective measures as either "highly representative," "somewhat representative," or "not at all representative" for the corresponding construct. All judges agreed that each item was at least "somewhat representative," while no item was perceived as "not at all representative," thus ensuring content validity (Katsikeas et al. 2006). Because some of the scales have never been used in an Asian context, we pretested the measures for validity and reliability as well as measurement invariance. Overall, the pilot study yielded excellent results (e.g., Cronbach's alpha for nostalgic brand positioning was .944 for China and .860 for Japan) and enabled us to establish full metric invariance as well as partial configural and scalar measurement invariance between the two countries (Steenkamp and Baumgartner 1998). In conclusion, 
Table 3 Measurements

\begin{tabular}{|c|c|c|c|c|}
\hline Construct and item wording & $\lambda$ & $\mathrm{CA}$ & $\mathrm{CR}$ & $\mathrm{M}(\mathrm{SD})$ \\
\hline \multicolumn{5}{|l|}{ Brand Equity (Yoo et al. 2000) } \\
\hline It makes sense to buy [BRAND] instead of another brand. & .801 & .921 & .922 & $4.622(1.148)$ \\
\hline $\begin{array}{l}\text { Even if another brand has the same features as [BRAND], } \\
\text { I would prefer to buy [BRAND]. }\end{array}$ & .880 & & & \\
\hline If there is another brand as good as [BRAND], I prefer to buy [BRAND]. & .886 & & & \\
\hline $\begin{array}{l}\text { If another brand is not different from [BRAND] in any way, } \\
\text { it seems smarter to purchase [BRAND]. }\end{array}$ & .888 & & & \\
\hline \multicolumn{5}{|l|}{$\begin{array}{l}\text { Nostalgic Brand Positioning (building on Ford et al. 2018; } \\
\text { Muehling and Sprott 2004) }\end{array}$} \\
\hline [BRAND] was around when I was a child. & .662 & .906 & .906 & $4.066(1.515)$ \\
\hline [BRAND] reminds me of the past. & .923 & & & \\
\hline $\begin{array}{l}\text { [BRAND] has a strong link to the past, which is still perpetuated } \\
\text { and celebrated to this day. }\end{array}$ & .848 & & & \\
\hline [BRAND] reminds me of the time when I was young. & .935 & & & \\
\hline \multicolumn{5}{|l|}{ Emotional Attachment (Batra et al. 2012) } \\
\hline I feel emotionally connected to [BRAND]. & .930 & .952 & .953 & $4.310(1.497)$ \\
\hline I feel a bond to [BRAND]. & .959 & & & \\
\hline [BRAND] feels like a good friend. & .909 & & & \\
\hline \multicolumn{5}{|l|}{ Brand Local Iconness (Steenkamp et al. 2003) } \\
\hline I associate this brand with things that are "Chinese/Japanese". & .719 & .830 & .833 & $4.591(1.287)$ \\
\hline To me, this brand represents what "China/Japan" is all about. & .866 & & & \\
\hline To me, this brand is a very good symbol of "China/Japan". & .779 & & & \\
\hline \multicolumn{5}{|l|}{ Brand Authenticity (Napoli et al. 2014) } \\
\hline [BRAND] remains true to its values. & .814 & .892 & .894 & $5.020(0.932)$ \\
\hline The brand always sticks to its principles. & .878 & & & \\
\hline This brand is guided by sincere values. & .882 & & & \\
\hline \multicolumn{5}{|l|}{ Brand Familiarity (Steenkamp et al. 2003) } \\
\hline [BRAND] is very familiar to me. & .860 & .732 & .745 & $5.170(1.149)$ \\
\hline I'm very knowledgeable about [BRAND]. & .625 & & & \\
\hline I can easily recognize [BRAND] among other brands. & .626 & & & \\
\hline \multicolumn{5}{|l|}{ Consumer Ethnocentrism (Steenkamp et al. 2003) } \\
\hline Purchasing foreign-made products is un-Chinese/un-Japanese. & .868 & .934 & .935 & $2.753(1.262)$ \\
\hline $\begin{array}{l}\text { Chinese/Japanese should not buy foreign products because this } \\
\text { hurts Chinese/Japanese business and causes unemployment. }\end{array}$ & .922 & & & \\
\hline A real Chinese/Japanese should always buy China/Japan-made products. & .881 & & & \\
\hline It is not right to purchase foreign products. & .862 & & & \\
\hline
\end{tabular}

$\lambda=$ standardized factor loadings $(\mathrm{CFA}) ; \mathrm{CA}=$ Cronbach's alpha; $\mathrm{CR}=$ Composite reliability

Goodness-of-fit statistics for the CFA: CFI $=.957 ; \mathrm{TLI}=.948 ; \mathrm{SRMR}=.050 ; \mathrm{RMSEA}=.060 ; \chi^{2}(231)=2151.430$

our measures are valid and applicable in an Asian context. Moreover, we include several covariates to account for possible influences of exogenous variance. Brand familiarity has been shown to exert influences on nostalgia effects and enhance brand equity (Ford et al. 2018). Consumer ethnocentrism is a necessary control when studying brand local iconness, as the mediation effect might be influenced by a consumer's predisposition toward ethnocentrism (Steenkamp et al. 2003). In addition, certain consumer demographics (i.e., age and gender) have been shown to influence the outcome of evoked nostalgia (e.g., Schindler and Holbrook 2003) and thus need to be controlled for.

We used the translation/back-translation approach to ensure idiomatic equivalence of our scales (Hult et al. 2008). Following this established method, the original English scales were translated into Chinese and Japanese, respectively, and then back-translated into English by bilingual marketing researchers. The translated version was corrected and the process was repeated until the two English versions fully corresponded with each other. 
We measured all items using seven-point Likert scales, with the exception of brand local iconness, for which we employed a semantic differential scale following the design of the original measure (Steenkamp et al. 2003). We again rigorously tested the scales for validity and reliability in our main study. The standardized factor loadings generally exceed 0.7. One exception is the item "[Brand] was around when I was a child" in our brand nostalgic positioning measure. This may indicate that nostalgic positioning does not necessarily need to share a connection with one's childhood but might encompass other pleasurable memories of the past (e.g., consumers' youth or adolescence) as well (Holbrook 1993). Furthermore, two items of our familiarity control variable are slightly below the 0.7 threshold. However, all constructs clearly exceed the average variance extract (AVE) threshold of .5 , and Cronbach's alpha coefficients for the measures range from 0.732 to 0.952 (Bagozzi and Yi 1988).

We checked for common method bias in our level 1 variables using a latent method factor (Podsakoff et al. 2003). A common variance of 0.074 and generally unchanged results with or without the factor suggest that common method variance is not distorting our results. In addition, we checked the variance inflation factor to test for multicollinearity. The factor ranges between 1.179 and $1.919(\mathrm{SD}=.292)$. These values are well below the suggested cutoff of 10 (Hair et al. 2009). ${ }^{2}$ The measurement model results (comparative fit index $[\mathrm{CFI}]=.957$; standardized root mean square residual [SRMR] $=.050$; root mean square error of approximation $[$ RMSEA $\left.]=.060 ; \chi^{2}(231)=2151.430\right)$ suggest a satisfactory model fit (Hair et al. 2009). We assessed discriminant validity among the study constructs using Fornell and Larcker's (1981) stringent procedure (see Table 4). After establishing reliability and validity for the study constructs, we modeled each construct using a weighted single indicator to reduce the model's complexity in testing the research hypotheses.

As we have indicated, the level 2 variables rely on different data sources than the level 1 variables. Specifically, level 2 variables include the emerging market difference measure, which is a dummy variable specifying the developed market as the baseline condition (i.e., 0) and the emerging market as the effect variable (i.e., 1). Brand innovativeness is based on the GlobalData product launch analytics database, as we have specified. The measure encompasses market introductions (i.e., commercialization of innovations), which are well suited to match the consumer perceptions that constitute our level 1 variables. Brand innovativeness measures the number of market introductions per brand in the two years prior to the

\footnotetext{
${ }^{2}$ Although these empirical results suggest that neither common method bias nor multicollinearity are of major concern, we still acknowledge that some correlations, especially between brand equity, emotional attachment and brand authenticity are comparatively high. However, the strong association between these variables is reflected in theory and previous research (e.g., Fritz et al. 2017; Park et al. 2010).
}

execution of our survey. Some products might not immediately be available in certain parts of a country (questioning a shorter time span), while consumers might be unable to recall innovations from a too-distant past (questioning a longer time span). Moreover, the diffusion of innovation is highly dependent on the type of innovation and the adopter (Rogers 2010). Weighting these factors, we consider two years a reasonable time span for the brand innovativeness measure. To test whether our results are distorted by strong variations in brand innovativeness over time, we also ran the data analysis with the number of innovations over the past three years, which yielded a similar pattern of results. While the direct effects of brand innovativeness on level 1 constructs are not the focus of the current research, they are still noteworthy. Brand innovativeness shares a negative (non-significant) correlation with brand equity as well as a negative correlation with brand authenticity (see Table 4). These effects point to an emerging research thread discussing potential downsides of innovativeness for brands. Previous findings suggest that strong brands initially struggle to reap innovation benefits and that too many innovations may be harmful, especially to brand authenticity (Beverland 2009; Brexendorf et al. 2015; Rubera 2015). In addition, in terms of level 2 variables, we control for product category differences pertaining to food (1) and non-food FMCGs (0), as product category differences have been found to moderate nostalgia effects (Kessous et al. 2015); pricing level, as the effect of low-price (0) and high-price (1) levels may have a different impact in emerging and developed markets; and brand reach, as the perception of domestic (0) and internationalized (1) brands may differ between emerging and developed market consumers (Heinberg et al. 2017).

Before developing the model, we had to take into account measurement invariance between Chinese and Japanese respondents. We followed the recommended procedure for large sample sizes (Chen 2007; Cheung and Rensvold 2002). Due to the chi-square test's susceptibility to sample size influences (Hair et al. 2009), goodness-offit indices, including the CFI, RMSEA, and SRMR, have been shown to detect non-invariance between groups of respondents more reliably. For our analysis, we relied on Chen's (2007) more stringent cutoff criteria, but we would equally meet the thresholds suggested in Cheung and Rensvold (2002). In the first step, we analyzed the measurement model presented in Table 3 separately for both countries. The individual analysis demonstrated good fit and discriminant validity (Model 1 and Model 2); therefore, we are able to establish configural invariance (Steenkamp and Baumgartner 1998). In the second step, one item loading in the measurement model of the constructs of nostalgic brand positioning, brand local iconness, and brand familiarity had to be freed to establish metric invariance (Model 5). One additional item intercept in the 
Table 4 Correlation matrix

\begin{tabular}{llllllll}
\hline & 1 & 2 & 3 & 4 & 5 & 6 \\
\hline 1 & Brand equity & .747 & .179 & .548 & .086 & .436 & .106 \\
2 & Nostalgic brand positioning & $.423^{* * *}$ & .721 & .242 & .106 & .143 & .000 \\
3 & Emotional attachment & $.740^{* * *}$ & $.492^{* * *}$ & .870 & .064 & .404 & .006 \\
4 & Brand local iconness & $.293^{* * *}$ & $.326^{* * *}$ & $.253^{* * *}$ & .625 & .103 & .004 \\
5 & Brand authenticity & $.660^{* * *}$ & $.378^{* * *}$ & $.636^{* * *}$ & $.321^{* * *}$ & .737 & .011 \\
6 & Emerging market difference & $.326^{* * *}$ & $.136^{* * *}$ & $.527^{* * *}$ & $.067^{* * *}$ & $.379^{* * *}$ & - \\
7 & Brand innovativeness & $-.001^{\text {n.s. }}$ & $.078^{* * *}$ & $.009^{\text {n.s. }}$ & $.105^{* * *}$ & $-.055^{* *}$ & $.041^{\text {n.s. }}$ \\
\hline
\end{tabular}

AVEs are in bold on the diagonal; squared correlations are above the diagonal; correlations are below the diagonal

$* p<.05 ; * * p<.01 ; * * * p<.001 ;$ n.s. $=$ not significant

measurement model of nostalgic brand positioning and one for brand equity were freed to establish scalar invariance (Model 7; Awanis et al. 2017) (see Table 5).

\section{Multilevel model specification}

We tested our model with the Mplus software (Muthén and Muthén 2017) using a robust maximum likelihood estimator. The method is in accordance with our sampling procedure, with observations on the individual level nested in the different brands on level 2. Using multilevel modeling with random slopes (coefficients) and random intercepts (means), we simultaneously controlled for variances caused by brand differences (i.e., emerging market difference, brand innovativeness, product category, pricing level, and brand reach) and consumer differences (i.e., brand perceptions, familiarity, psychographics). In other words, we disentangle information contained in our variables simultaneously at two levels and thus avoid an aggregation bias, often associated with multigroup procedures (Hox 2010). The level 1 equations for our dependent variable brand equity are as follows:

$$
\begin{aligned}
B E_{i j}= & \beta_{0 j}+\beta_{1 j}\left(E A_{i j}\right)+\beta_{2 j}\left(B L I_{i j}\right)+\beta_{3}\left(B A_{i}\right) \\
& +\beta_{\text {controls }}\left(F \text { Controls }_{i j}\right)+r_{i j} \\
E A_{i j}= & \beta_{4}+\beta_{5 j}\left(N B P_{i j}\right)+\beta_{\text {controls }}\left(F_{C^{\prime} o n t r o l s}\right)+r_{1 i j} \\
B L I_{i j}= & \beta_{6}+\beta_{7 j}\left(N B P_{i j}\right)+\beta_{\text {controls }}\left(\text { CControls }_{i j}\right)+r_{2 i j}(1,3 \\
B A_{i}= & \beta_{8}+\beta_{9}\left(N B P_{i}\right)+\beta_{\text {controls }}\left(\text { FControls }_{i}\right)+r_{3 i}
\end{aligned}
$$

Here, $i$ represents consumers and $j$ brands, and $B E_{i j}$ denotes individual $i$ 's brand equity perception toward brand $j$. Likewise, $E A, B L I, B A$, and NBP stand for emotional attachment, brand local iconness, brand authenticity, and nostalgic brand positioning, respectively. FControls includes the consumer-level control variables. $\beta_{0 j}$ signifies the random intercept of brand equity, which we have included for control purposes. $\beta_{4}, \beta_{6}$, and $\beta_{8}$ are the fixed intercepts of emotional attachment, brand local iconness, and brand authenticity. $\beta_{1 j}, \beta_{2 j}, \beta_{5 j}$, and $\beta_{7 j}$ are the labels for the regression slopes that are allowed to vary across brands; the product of the first and third slope coefficient forms

\begin{tabular}{|c|c|c|c|c|c|c|}
\hline Model & CFI & $\Delta \mathrm{CFI}$ & RMSEA & $\Delta$ RMSEA & SRMR & $\Delta \mathrm{SRMR}$ \\
\hline \multicolumn{7}{|l|}{ Invariance test among Chinese and Japanese respondents } \\
\hline Model 1 (China): & .968 & - & .054 & - & .044 & - \\
\hline Model 2 (Japan): & .949 & - & .060 & - & .051 & - \\
\hline \multicolumn{7}{|c|}{ Configural invariance: good fit, factor loadings significantly different from zero, discriminant validity for both models } \\
\hline Model 3 (combined baseline model of free factor loadings \& intercepts) & .961 & - & .057 & - & .047 & - \\
\hline Model 4 (fixed factor loadings against Model 3) & .950 & .011 & .063 & .006 & .096 & .049 \\
\hline Model 5 (partially fixed factor loadings against Model 3) & .959 & .002 & .059 & .002 & .072 & .025 \\
\hline \multicolumn{7}{|l|}{ Metric invariance established } \\
\hline Model 6 (fixed intercepts and partially fixed factor loadings against Model 5) & .937 & .022 & .069 & .010 & .081 & .009 \\
\hline Model 7 (partially fixed intercepts and partially fixed factor loadings against Model 5) & .950 & .009 & .062 & .003 & .074 & .002 \\
\hline
\end{tabular}
the mediation through emotional attachment, whereas the product of the other two slope coefficients denotes the mediation through brand local iconness. $\beta_{3 j}$ and $\beta_{9 j}$ are fixed regression

Table 5 Measurement invariance 
slopes, as we have not hypothesized random brand effects for mediation through brand authenticity based on theoretical considerations. $r_{i j}$ through $r_{3 i}$ denote the error terms on the consumer level. Following Raudenbush and Bryk's (2002) suggestion, we group-mean-centered the independent variables for better numerical stability and to avoid model misspecification. We included the direct effect of nostalgic brand positioning in the model to test the three mediators and then dropped it from the final model because it did not cross the significance threshold.

At the brand level, we specify the dichotomous variable emerging market difference $\left(E M D_{j}\right)$, brand innovativeness $\left(B I_{j}\right)$, and the interaction effect between the two $\left(E M D_{j} * B I_{j}\right)$. In addition, the variable $F C o n t r o l_{j}$ controls for influences from product category, pricing level, and brand reach. We specify the level 2 equations as follows:

$$
\begin{aligned}
\beta_{0 j}= & \gamma_{00}+\gamma_{01}\left(E M D_{j}\right)+\gamma_{02}\left(B_{j}\right) \\
& +\gamma_{03}\left(E M D_{j} * B I_{j}\right)+\gamma_{\text {control }}\left(\text { FControl }_{j}\right)+u_{0 j} \\
\beta_{1 j}= & \gamma_{10}+\gamma_{11}\left(E M D_{j}\right)+\gamma_{12}\left(B I_{j}\right) \\
& +\gamma_{13}\left(E M D_{j} * B I_{j}\right)+\gamma_{\text {control }}\left(\text { FControl }_{j}\right)+u_{1 j} \\
\beta_{2 j}= & \gamma_{20}+\gamma_{21}\left(E M D_{j}\right)+\gamma_{22}\left(B I_{j}\right) \\
& +\gamma_{23}\left(E M D_{j} * B I_{j}\right)+\gamma_{\text {control }}\left(\text { FControl }_{j}\right)+u_{2 j} \\
\beta_{5 j}= & \gamma_{50}+\gamma_{51}\left(E M D_{j}\right)+\gamma_{52}\left(B_{j}\right) \\
& +\gamma_{53}\left(E M D_{j} * B I_{j}\right)+\gamma_{\text {control }}\left(\text { FControl }_{j}\right)+u_{5 j} \\
\beta_{7 j}= & \gamma_{70}+\gamma_{71}\left(E M D_{j}\right)+\gamma_{72}\left(B_{j}\right) \\
& +\gamma_{73}\left(E M D_{j} * B I_{j}\right)+\gamma_{\text {control }}\left(\text { FControl }_{j}\right)+u_{7 j}
\end{aligned}
$$

The error terms $u$ are normally distributed. Substituting Eqs. 2.1-2.5 into Eqs. 1.1-1.4 yields the following equations, which we estimated jointly relying on a robust maximum likelihood estimator to test the hypotheses:

$$
\begin{aligned}
B E_{i j}= & \gamma_{00}+\gamma_{01}\left(E M D_{j}\right)+\gamma_{02}\left(B I_{j}\right)+\gamma_{03}\left(E M D_{j}{ }^{*} B I_{j}\right) \\
& +\left[\gamma_{10}+\gamma_{11}\left(E M D_{j}\right)+\gamma_{12}\left(B I_{j}\right)+\gamma_{13}\left(E M D_{j}^{*} B I_{j}\right)\right]\left(E A_{i j}\right) \\
& +\left[\gamma_{20}+\gamma_{21}\left(E M D_{j}\right)+\gamma_{22}\left(B I_{j}\right)+\gamma_{23}\left(E M D_{j}^{*} B I_{j}\right)\right]\left(B L I_{i j}\right) \\
& +\beta_{3}\left(B A_{i}\right)+Y_{\text {controls }}{ }^{*} \text { Fontrols }_{i j}+\text { error }
\end{aligned}
$$

$E A_{i j}=\beta_{4}+\left[\gamma_{50}+\gamma_{51}\left(E M D_{j}\right)+\gamma_{52}\left(B I_{j}\right)+\gamma_{53}\left(E M D_{j}{ }^{*} B I_{j}\right)\right]\left(N B P_{i j}\right)+Y_{\text {controls }}{ }^{*}$ FControls ${ }_{i j}+$ error

$B L I_{i j}=\beta_{6}+\left[\gamma_{70}+\gamma_{71}\left(E M D_{j}\right)+\gamma_{72}\left(B I_{j}\right)+\gamma_{73}\left(E M D_{j}^{*} B I_{j}\right)\right]\left(N B P_{i j}\right)+Y_{\text {controls }^{*}}{ }^{*}$ FControls $s_{i j}+\operatorname{error}\left(N B P_{i j}\right)$

$B A_{i}=\beta_{8}+\beta_{9}\left(N B P_{i}\right)+\beta_{\text {controls }}\left(\right.$ FControls $\left._{i}\right)+$ error

\section{Results}

We follow Zhou et al. (2010) and apply a stepwise procedure. First, we check the brand-level variance in relation to the individual-level variance ( $\mathrm{Null}$ model) and obtain a coefficient of 0.156 , which is generally regarded as medium-sized (Hox 2010). Next, we add control variables (Fixed effects baseline model) and predictors (Full individual model) to the individual level. The Random effects baseline model adds the control variables to the brand level, while the Full model includes the random intercepts and slopes as specified in Eqs. 3.13.4. The five models reveal an increase in model fit and a steady decline of residual variance (Table 6), which provides good support for the proposed model (Zhou et al. 2010).

To examine H1a-H1c, we first assess the path coefficients in the random effects baseline model and find significant, positive effects for all relationships (nostalgia-emotional attachment: $b=0.397, p<.001$; emotional attachment-brand equity: $b=0.478, p<.001$; nostalgia-brand local iconness: $b=0.198, p<.001$; brand local iconness-brand equity: $b=$ $0.044, p<.05$; nostalgia-brand authenticity: $b=0.198$, $p<.001$; brand authenticity-brand equity: $b=0.326$, $p<.001)$. Next, we test for mediation by relying on Bayesian credibility intervals. Mediation and moderated mediation hypotheses are usually assessed using bootstrap confidence intervals (e.g., Hayes 2013). However, bootstrapping for multilevel models is still at its infancy and, to date, is not possible in most software packages, including Mplus. Instead, we employ Bayesian analysis to calculate credibility intervals, which are nonsymmetric intervals just like those calculated using bootstrapping procedures and thus can be interpreted similarly for moderated mediation analyses (Muthén 2015). The $95 \%$ credibility intervals clearly exclude zero and thus support the mediation hypotheses. Mediation through emotional attachment $\left(a_{1} * b_{1}\right)$ results in a credibility interval of [0.170;0.228], mediation through brand local iconness $\left(a_{2} * b_{2}\right)$ results in a credibility interval of [0.003; 0.016], and mediation through brand authenticity $\left(a_{3} * b_{3}\right)$ results in a credibility interval of $[0.055 ; 0.077]$. In addition, the direct effect of nostalgic brand positioning on brand equity, which is significant without the mediators $[0.241 ; 0.298]$, decreases in size and ceases to cross the significance threshold after inclusion of the mediators $[-0.038 ; 0.035]$. Therefore, we do not include the direct effect in our further calculations and, in summary, find support for H1a-H1c.

To assess the moderation of the mediation effect through emotional attachment, we first consider the differences between an emerging market (effects variable) and a developed market (baseline condition). $\mathrm{H} 2 \mathrm{a}$ predicts that mediation through emotional attachment is weaker in emerging markets. We find support for $\mathrm{H} 2$ a because the $95 \%$ credibility interval of this difference excludes zero $[-0.023 ;-0.002]$. Next, we evaluate the moderation of brand innovativeness, again 
Table 6 Results of hierarchical linear modeling

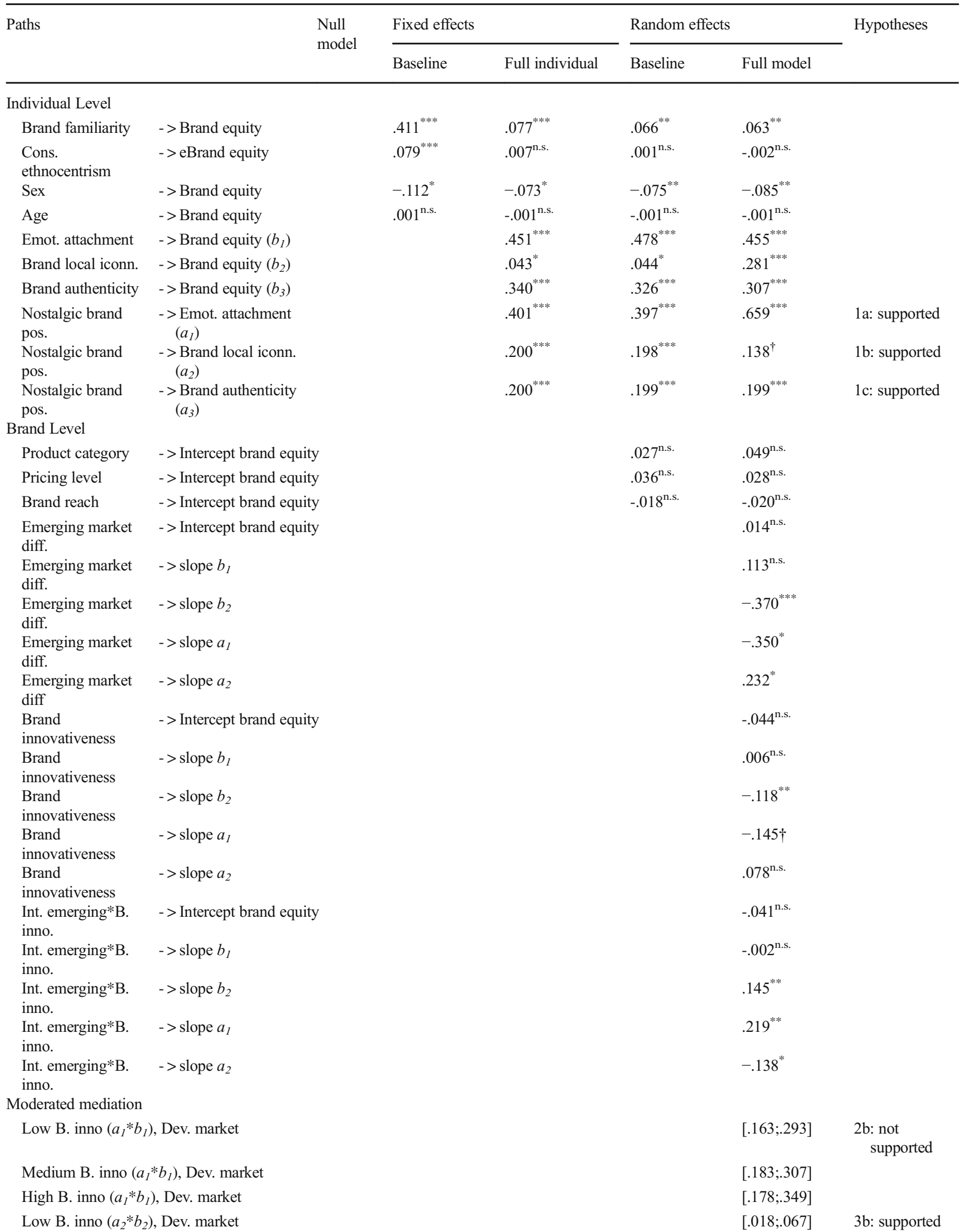


Table 6 (continued)

\begin{tabular}{|c|c|c|c|c|c|c|}
\hline \multirow[t]{2}{*}{ Paths } & \multirow{2}{*}{$\begin{array}{l}\text { Null } \\
\text { model }\end{array}$} & \multicolumn{2}{|c|}{ Fixed effects } & \multicolumn{2}{|c|}{ Random effects } & \multirow[t]{2}{*}{ Hypotheses } \\
\hline & & Baseline & Full individual & Baseline & Full model & \\
\hline \multicolumn{2}{|l|}{ Medium B. inno $\left(a_{2} * b_{2}\right)$, Dev. market } & & & & {$[.009 ; .049]$} & \\
\hline \multicolumn{2}{|l|}{ High B. inno $\left(a_{2} * b_{2}\right)$, Dev. market } & & & & {$[-.021 ; .048]$} & \\
\hline \multicolumn{2}{|l|}{ Low B. inno $\left(a_{1}^{*} b_{1}\right)$, Emerging market diff. } & & & & {$[-.033 ;-.003]$} & \\
\hline \multicolumn{2}{|l|}{ Medium B. inno $\left(a_{1} * b_{1}\right)$, Emerging market diff. } & & & & {$[-.023 ;-.002]$} & 2a: supported \\
\hline \multicolumn{2}{|l|}{ High B. inno $\left(a_{1} * b_{1}\right)$, Emerging market diff. } & & & & {$[-.024 ; .004]$} & 2c: supported \\
\hline \multicolumn{2}{|l|}{ Low B. inno $\left(a_{2} * b_{2}\right)$, Emerging market diff. } & & & & {$[-.066 ;-.002]$} & \\
\hline \multicolumn{2}{|l|}{ Medium B. inno $\left(a_{2} * b_{2}\right)$, Emerging market diff. } & & & & {$[-.024 ; .008]$} & $\begin{array}{l}\text { 3a: part. } \\
\text { supported }\end{array}$ \\
\hline \multicolumn{2}{|l|}{ High B. inno $\left(a_{2} * b_{2}\right)$, Emerging market diff. } & & & & {$[-.008 ; .017]$} & 3c: supported \\
\hline $\begin{array}{l}\text { Residual variance brand equity (individual } \\
\text { level) }\end{array}$ & 1.025 & .826 & .377 & & & \\
\hline Residual variance brand equity (brand level) & 0.189 & & & .016 & .014 & \\
\hline \multicolumn{2}{|l|}{ Chi-squares diff test to previous model } & $\begin{array}{l}307.1(4) \\
\quad p<.001\end{array}$ & $\begin{array}{c}2118.1(19) \\
\quad p<.001\end{array}$ & $\begin{array}{l}113.6(7) \\
p<.001\end{array}$ & $\begin{array}{l}87.2(21) \\
\quad p<.001\end{array}$ & \\
\hline
\end{tabular}

$\dagger p<.1, * p<.05, * * p<.01, * * * p<.001$

selecting the developed market as the baseline condition (H2b) and then assessing differences from this baseline effect in emerging markets $(\mathrm{H} 2 \mathrm{c})$. To evaluate the moderated mediation effects, we construct $95 \%$ credibility intervals, this time at low, medium, and high levels of brand innovativeness. The medium level of innovativeness is defined as the mean of the number of innovations per brand in our sample, while the low and high levels of innovativeness lie one standard deviation below and above the mean, respectively. As such, we can monitor if a mediator increases or decreases in importance depending on the level of brand innovativeness. H2b predicts that the strength of the mediation of emotional attachment increases with the level of brand innovativeness in developed markets. Although we witness a slight increase of the effect of the mediator (low brand innovativeness: [0.163; 0.293]; medium brand innovativeness: [0.183; 0.307]; high brand innovativeness: $[0.178 ; 0.349]$ ), the mediation effect is not suppressed entirely for lower levels of innovativeness (Hayes 2013). In addition, the difference between the indirect effect under high versus low levels of brand innovativeness is not significant $(p=.213)$. As such, our results do not support $\mathrm{H} 2 \mathrm{~b}$. H2c predicts that the country effect difference for mediation decreases with higher levels of brand innovativeness. Again, we assess the credibility intervals and find that the difference between emerging and developed markets diminishes with high levels of brand innovativeness (low: $[-0.033$; $-0.003]$; medium: $[-0.023 ;-0.002]$; high: $[-0.024 ; 0.004]$ ), resulting in a non-significant mediation difference between both country groups for the last condition. The results provide additional support for $\mathrm{H} 2 \mathrm{c}$, as the difference between the indirect effects under high versus low levels of brand innovativeness is significant $(p<.05)$.
We emphasize that the rejection $\mathrm{H} 2 \mathrm{~b}$ and the acceptance of $\mathrm{H} 2 \mathrm{c}$ is not contradictory, as both hypotheses build on different logics. The reason for the rejection of $\mathrm{H} 2 \mathrm{~b}$ may be that innovations are a double-edged sword for nostalgically positioned brands, raising brand relevance but also blurring a brand's past image. This does not contradict the logic of $\mathrm{H} 2 \mathrm{c}$, which argues that innovative brands in emerging markets are less hampered from fierce competition and low loyalty effects. As such, the rejection of $\mathrm{H} 2 \mathrm{~b}$ does not raise any doubt concerning the overarching theoretical model.

$\mathrm{H} 3 \mathrm{a}-\mathrm{H} 3 \mathrm{c}$ target the moderation of the mediating effect via brand local iconness. H3a predicted a weaker emerging market effect for mediation through brand local iconness. The analysis shows that although the difference test between both countries does not cross the significance threshold (with a $95 \%$ credibility interval of $[-0.024 ; 0.008])$, the mediation itself is significant in developed markets (a 95\% credibility interval of $[0.009 ; 0.049])$ but non-significant in emerging markets $[-0.004 ; 0.050]$. Even selecting a stricter interval for the developed market (a 99\% credibility interval of [0.002; $0.058]$ ) and a more relaxed one for the emerging market (a $90 \%$ credibility interval of $\left[\begin{array}{lll}-0.001 & 0.046\end{array}\right]$ ) still supports the difference in mediation, thus displaying an effect of the brand local iconness mediator in the developed market context but not in the emerging market context. Thus, the results provide partial support for $\mathrm{H} 3 \mathrm{a}$.

Regarding the moderation of brand innovativeness, we find that the mediating effect of brand local iconness decreases with increasing brand innovativeness in developed markets, in support of $\mathrm{H} 3 \mathrm{~b}$. We witness a decreasing trend of the mediator brand local iconness with increasing levels of brand innovativeness (low: [0.018; 0.067]; medium: [0.009; 
0.049]; high: $[-0.021 ; 0.048])$, resulting in a non-significant mediation effect for the last condition. We obtain additional support for the significant influence of brand innovativeness, as the test of difference between the indirect effect under high versus low levels of brand innovativeness is marginally significant $(p<.1)$ Similarly, we also find support for $\mathrm{H} 3 \mathrm{c}$, as the negative country effect of emerging markets with respect to the brand local iconness mediator disappears with increasing levels of brand innovativeness (low: $[-0.066 ;-0.002]$; medium: $[-0.024 ; 0.008]$; high: $[-0.008 ; 0.017])$. This finding is supported by a significant difference between high versus low levels of brand innovativeness for the respective indirect effect $(p<.05)$.

\section{Additional analysis}

Our results demonstrate that combining the different nostalgic brand relationship dimensions is important, as previous studies have only investigated the effects individually. To further explore the combinations of these dimensions, we examine if each individual mediator explains additional variance of the dependent variable brand equity. We obtain confirmation of this test and additionally find evidence that the mediating processes even enhance one another (details provided in Web Appendix 2). As such, there is an interplay between nostalgic brand relationship dimensions, which may reflect the interlinkages between different aspects of distance noted in construal level theory (Liberman and Trope 2008).

In addition, one might raise the question, if the three mediating processes of the nostalgic brand positioning-brand equity link are a generic mechanism, which might be applied equally well to other positioning strategies. We ran additional analyses with functional brand positioning as an alternative positioning strategy (see Web Appendix 3) and find that the mediating processes of nostalgic brand positioning are stronger than those of functional brand positioning. Moreover, the three mediators do not fully explain the relationship between functional brand positioning and brand equity, suggesting that additional or alternative processes may describe the mechanism better. As such, we conclude that the mechanism we have selected to explain the nostalgic brand positioning strategy is not a generic one; on the contrary, the combination of mediators examined here is unique to nostalgic brand positioning.

The moderators (country differences and brand innovativeness) that we have introduced to the mediating mechanism should be viewed as the starting point of similar research endeavors. Additional country-level factors, firm-level factors, and individual-level factors may affect the mediating mechanism. We ran initial analyses and find that the firmlevel factor of corporate social responsibility does not moderate the links of the three mediators (see Web Appendix 4). The individual cultural trait of consumer ethnocentrism does have some degree of moderating influence (see Web Appendix 5), but this influence does not bias our empirical investigation because we control for consumer ethnocentrism. Finally, individual-level demographics (sex, age, education) do not moderate the mediating mechanism (see Web Appendix 6).

As we have outlined, nostalgic brand positioning is measured in terms of consumer perceptions. To demonstrate that these perceptions are indeed influenced by the actual brand positioning intended by the firm, we regressed brand age (considering that older brands are more likely to exhibit a nostalgic brand positioning) onto perceived nostalgic positioning. We find clear support for this relationship, suggesting a robust effect $(b=.421)$ between brand age and perceived brand positioning (see Web Appendix 7).

Finally, we conducted further analyses to examine any possible moderating effects on the mediation that we originally excluded from hypotheses development due to the absence of theory-based rational (i.e., moderating effects of country differences, brand innovativeness, and their interaction on the link between nostalgic brand positioning, brand authenticity, and brand equity). We find that the mediation effect in developed markets is significant regardless of the different levels of brand innovativeness (low: [.022;.076]; medium: [.037;.095]; high $[.044 ; 136])$ and that there is neither a country difference nor an interaction between the two effects (low: [-.007;013]; medium: $[-.003 ; .005]$; high $[-.015 ; .005])$. Therefore, as expected, we found no significant moderating effects, which aligns with the absence of any meaningful conceptual rational.

\section{Discussion}

While most research has focused on consumers' predispositions for nostalgia (Ford et al. 2018), little work has taken a holistic perspective on the different channels through which nostalgic brand positioning leads to brand equity (or related constructs) or asked if these different channels are subject to certain moderating effects, such as the country setting or brand innovativeness. We employ a multilevel moderated mediation analysis, and our findings show that emotional attachment, brand local iconness, and brand authenticity mediate the nostalgic brand positioning-brand equity relationship and thus are fundamental nostalgic brand relationship dimensions. In other words, the three processes explain why the established main effect of nostalgic brand positioning (e.g., Gineikiene and Diamantopoulos 2017) occurs.

Moreover, we find that country setting constitutes an important boundary condition to these mediating effects. Specifically, the links through emotional attachment and brand local iconness are significantly weaker in emerging markets than in developed markets. As such, these two nostalgic brand relationship dimensions (which reflect the social and spatial aspects of distance) are less effective facilitators of 
a nostalgic brand positioning in emerging markets. Despite the immense market potential of brand strategies built around nostalgia in both developed and emerging markets, this important research perspective has not been addressed previously. Moreover, lay theories about which market (i.e., emerging or developed) is better suited for nostalgia strategies have pointed in opposite directions (e.g., Barry 2016; Euromonitor 2012).

Regarding brand innovativeness, we find that nostalgic positioned brands in developed markets do not profit from enhanced innovativeness; in contrast, brands in emerging markets benefit from increasing levels of brand innovativeness. Specifically, the mediating link through emotional attachment did not increase significantly for higher levels of brand innovativeness in developed markets. Moreover, the mediating link through brand local iconness decreased and even became non-significant for highly innovative brands. In other words, a high level of brand innovativeness does not facilitate effects of a nostalgic brand positioning on brand equity in developed markets; on the contrary, it impedes this effect. Our research, therefore, contributes to a better understanding of the downsides of innovations for brand equity, a call voiced by Brexendorf et al. (2015). In emerging markets, however, nostalgic positioned brands can benefit from innovation, as the negative country effects for emerging markets exist only for low and medium levels of brand innovativeness. As such, the country moderator (or context effects on a more abstract level) may explain the disagreement in the literature about the interplay of nostalgic brand positioning and brand innovativeness (e.g., Brown et al. 2003; Shields and Johnson 2016).

\section{Contributions to knowledge}

In psychology research, construal level theory has served as a grid for dissecting consumer dispositions to nostalgia along different aspects of distance (i.e., social, spatial, and temporal; e.g., Stephan et al. 2012; Wildschut et al. 2006, 2010). The present study transfers these psychology-based nostalgia perspectives to the effects of nostalgic brand positioning on brand equity and identifies three nostalgic brand relationship dimensions (i.e., emotional attachment, brand local iconness, and brand authenticity), which constitute important mediators for the nostalgic brand positioning-brand equity relationship. In addition to retesting the theory in a branding context, the present study adds to the understanding of the unique nature of nostalgia from a construal level theory perspective. The interplay between higher-level construal (abstract, past-related) and lower-level construal (concrete, connecting the past to the present) has been identified as a condition for nostalgia effects (Stephan et al. 2012). However, implications of this interplay have not been fully considered. The present study demonstrates that certain moderators can facilitate or disturb this interplay and, in turn, increase or decrease effects of nostalgic brand positioning on brand equity. For example, factors such as increased "noise"-in our case caused by the numerous competitors present in emerging markets and emerging market consumers' propensity to trade up - can impede the connection of the past to the present. Consequently, forming emotional attachments is more difficult for nostalgic positioned brands in emerging markets.

Furthermore, for the nostalgia effect to play a facilitating role, nostalgia elements need to be related to positive attributes; this constitutes an internal prerequisite of the effect. Such a positive attribution is missing for the nostalgic brand relationship dimension of brand local iconness in emerging markets. Although we observe an increased effect of brand local iconness after a nostalgic positioning of the brand, the effect does not carry over to brand equity, as local brands are less favored than foreign brands in emerging markets.

Moreover, a drastic change of brand image over time could obstruct the interplay between higher-level and lower-level construal. We observe such an effect for highly innovative brands in developed markets. According to the literature, high innovativeness increases the global appeal of a brand (Steenkamp and De Jong 2010), and a global appeal may in turn obstruct the effects of brand local iconness (Heinberg et al. 2017). As such, highly innovative brands face a weaker effect of local iconness on brand equity in developed markets. On a more abstract level, one might argue that the change of brand image over time hinders the interplay between higherlevel construal, which signifies the brand's past, and lowerlevel construal, which connects the brand's past to the present.

Finally, some moderators might have conflicting effects. For example, brand innovativeness could contribute to enhancing the psychic distance of a brand by reducing the clarity of its past image; however, brand innovativeness could also enhance the relevance of the brand to the consumer in the present and thus facilitate the emotional connection he or she feels with the brand. Interestingly, our hypothesis regarding the effect of brand innovativeness on mediation via emotional attachment did not receive support, possibly because of the previously mentioned conflicting effects. Nonetheless, given the tentative nature of this reasoning, a more in-depth investigation of such conflicting moderating effects presents an intriguing opportunity for future research.

\section{Managerial implications}

Marketing managers face the challenge of needing to create an emotional hook for consumers in an increasingly digital and impersonal world (Friedman 2016). Furthermore, brand equity is of vital interest to managers because it is connected to both the top line and the bottom line of a company's balance sheet (e.g., Ailawadi et al. 2003; Rego et al. 2009). Nostalgiacentric branding strategies might prove valuable in this regard, but to tap the benefits of nostalgic brand positioning and 
enhance brand equity, managers need to be aware that this process is facilitated along different channels, namely, via emotional attachment, brand local iconness, and brand authenticity. Importantly, this combination of linkages is unique to nostalgic brand positioning, as other positioning strategies, such as functional brand positioning, would be related to a different set of processes that explain the mechanism for how brand positioning creates brand equity. Moreover, our results indicate that brand age is related to nostalgic brand positioning; therefore, nostalgic brand positioning would be a particular attractive strategy for older brands.

Our study reveals that the mediating mechanism between nostalgic brand positioning and brand equity is subject to moderating contextual factors (e.g., country setting) and firm -/brand-related factors (e.g., brand innovativeness), which holds important implications for business strategy. In developed markets, brand innovativeness does not facilitate the creation of brand equity for nostalgic positioned brands. While we do not find support for an enhancing effect through emotional attachment, our results reveal that the effect through brand local iconness decreases with increasing innovativeness of a brand. To circumvent this effect, managers should take care to adapt innovations to the particular country context, as certain standardizations associated with innovations of nostalgic products can lead to a loss of home-associations with the brand (Steenkamp and De Jong 2010). In line with this reasoning, we advise managers to revert to local symbols of childhood and strong ties to the specific country as a means to position a brand nostalgically rather than including global/ universal symbols of childhood (e.g., marbles, or a hopscotch game). Moreover, managers should assess performance innovations separately from design innovations. While performance innovations are necessary to maintain the relevance of a product to consumers (Beverland et al. 2010), we suggest that design innovations should be minimal for nostalgic positioned brands and should not inhibit key elements that relate to the local origin of the brand and stress a commitment to home. Considering the sizable investments typically associated with innovations (Brexendorf et al. 2015), such a strategy may help firms avoid the negative effect of innovations revealed in the present study.

In contrast to developed markets, nostalgic positioned brands in emerging markets can profit from high levels of brand innovativeness and should thus embrace a different approach. In emerging markets, brand innovativeness attenuates the negative country effect and thus facilitates the effects of nostalgic brand positioning on brand equity via emotional attachment and brand local iconness. Emerging market consumers with evolving product expectations and increasing spending power are more open to innovations of nostalgic positioned brands. Innovations there help nostalgic positioned brands stand out from competitors and stay relevant to consumers. In addition, nostalgic brands may use advertising campaigns that stress their humble beginnings and their growth story through their customers' lifetime to become an innovative and successful brand. Such a strategy may shift the brand image from the past, when local brands were unable to keep up with foreign brands in terms of quality and prestige, to a story of development and momentum. Such a strategy may circumvent the weak link between brand local iconness and brand equity in emerging markets. Moreover, such a strategy could facilitate the nostalgic brand relationship dimension of emotional attachment because it links the brand's evolution to the consumers' own development and thus contributes to consumers' actual self-congruence (Malär et al. 2011).

\section{Limitations and future research}

Several limitations should be noted that, in turn, point to future research opportunities. First, our moderator of brand innovativeness was conceptualized as new product introductions over a set time span of two years. While we added reliability to our results by finding comparable effects for different time spans, we cannot draw any definitive conclusion as to how long it takes for innovations after their market introduction to have an effect on the success of nostalgic brand positioning. Brand strategies might switch over time, and a longitudinal study design would better capture such a dynamic process. In addition, such a design may also examine the number of interactions involved in the process of building attachment with a brand and the interacting role of brand innovativeness.

Second, we did not consider the relevance of cultural factors in influencing the effects of how nostalgic brand positioning leads to brand equity. Indeed, we chose not to include cultural factors, as previous studies have not unveiled significant influences of culture on nostalgia effects (Hepper et al. 2014; Steenkamp et al. 1999). Nevertheless, given the presence of cultural differences across countries with respect to long-term orientation (Gürhan-Canli et al. 2018; Hofstede and Minkov 2010; Lin and Kalwani 2018), it would be interesting for future research to examine whether certain specific cultural dimensions (e.g., long-term orientation) affect the nostalgic brand relationship dimension of brand authenticity (which relates to the temporal distance aspect of construal theory). By comparing developed Western countries with Eastern emerging markets, future researchers could investigate the influence of culture as well as the interaction of culture and country development on the effects of nostalgic brand positioning on brand equity.

Third, our study only is a start to understand the moderating factors on the mediating processes of nostalgic brand positioning. While we focus on brand- and country-level moderating factors, an extended exploration of these would be a worthwhile avenue for further research. For example, what role does animosity between two countries play (Gineikiene and Diamantopoulos 2017), and how does it differ between 
foreign and local brands with a nostalgic brand positioning? How can changes in politico-economic conditions affect the strength of individual mediators? Furthermore, firm-level factors such as marketing-mix efforts, social media activities, or unethical marketing practices may have an effect (Gao et al. 2018). Such research would enable firms to better link brand nostalgia in specific countries with their global marketing strategy. A longitudinal study would be appropriate for investigating such research questions. Moreover, our study did not pay sufficient attention to consumers' psychological traits (e.g., consumer innovativeness), their personality dimension, or their individual cultural orientation (e.g., consumer ethnocentrism). Future research might investigate the relevance of such variables in influencing the role of our three proposed mediators. In addition, researchers should investigate possible moderating effects of consumer demographics on our brand nostalgic positioning-brand equity framework. While we control for demographic factors such as age and gender and did not find moderating effects in our additional analyses (refer to Web Appendix 6), the role of consumer demographics (including effects of income, education, or locality) warrants a more detailed analysis. Still another area of research is to examine contingency effects regarding our moderators. For example, future research should consider other product categories as well as brands with specific pricing strategies and market shares.

Finally, brand positioning may be multidimensional. For example, firms may employ a nostalgic brand positioning in combination with a functional or a symbolic positioning strategy. The interaction between different positioning strategies has not received sufficient attention in the literature and thus provides an important opportunity for future research.

Open Access This article is distributed under the terms of the Creative Commons Attribution 4.0 International License (http:// creativecommons.org/licenses/by/4.0/), which permits unrestricted use, distribution, and reproduction in any medium, provided you give appropriate credit to the original author(s) and the source, provide a link to the Creative Commons license, and indicate if changes were made.

Publisher's note Springer Nature remains neutral with regard to jurisdictional claims in published maps and institutional affiliations.

\section{References}

Aaker, D. A. (1991). Managing brand equity: Capitalizing on the value of a brand name. New York: Free Press.

Aaker, D. A. (2012). Win the brand relevance battle and then build competitor barriers. California Management Review, 54(2), 43-57.

Ailawadi, K., Lehmann, D., \& Neslin, S. (2003). Revenue premium as an outcome measure of brand equity. Journal of Marketing, 67(4), 1-17.

Anestis, M., Hsu, H., Hui, V., \& Liao. C. (2008). Report: Foreign or local brands China. BCG Focus. Retrieved July 7, 2012 from http:// image-src.bcg.com/Images/BCG_Foreign_or_Local_Brands_ China_Jun_2008_ENG_tcm55-1619̄01.pdf.
Atsmon, Y., Dixit, V., Magni, M., \& St-Maurice, I. (2010). China's new pragmatic consumers. Retrieved May 20, 2011 from https://www. mckinseyquarterly.com/PDFDownload.aspx?ar=2683.

Atsmon, Y., Kuentz, J.-F., \& Seong J. (2012). Building brands in emerging markets. McKinsey Quarterly. Retrieved October 16, 2012 from https://www.mckinsey.com/business-functions/marketing-andsales/our-insights/building-brands-in-emerging-markets.

Awanis, S., Schlegelmilch, B. B., \& Cui, C. C. (2017). Asia's materialists: Reconciling collectivism and materialism. Journal of International Business Studies, 48(8), 964-991.

Bagozzi, R. P., \& Yi, Y. (1988). On the evaluation of structural equation models. Journal of the Academy of Marketing Science, 16(1), 74-94.

Ball, A. D., \& Tasaki, L. H. (1992). The role and measurement of attachment in consumer behavior. Journal of Consumer Psychology, 1(2), $155-172$.

Barry, M. (2016). Crystal Pepsi strikes back: Can nostalgia revive carbonates sales? Euromonitor, 23 September.

Batra, R., Ramaswarny, V., Alden, D. L., Steenkamp, J.-B. E. M., \& Ramachander, S. (2000). Effects of brand local and nonlocal origin on consumer attitudes in developing countries. Journal of Consumer Psychology, 9(2), 83-95.

Batra, R., Ahuvia, A. C., \& Bagozzi, R. P. (2012). Brand love. Journal of Marketing, 76(2), 1-16.

BBC. (2009). Hollister branding “fictitious.” Retrieved April 4, 2018 from http://news.bbc.co.uk/1/hi/business/8340453.stm.

Beverland, M. B. (2005). Managing the design innovation-brand marketing interface: Resolving the tension between artistic creation and commercial imperatives. Journal of Product Innovation Management, 22(2), 193-207.

Beverland, M. B. (2009). Building brand authenticity: Seven habits of iconic brands. New York: Palgrave Macmillan.

Beverland, M. B., Napoli, J., \& Farrelly, F. (2010). Can all brands innovate in the same way? A typology of brand position and innovation effort. Journal of Product Innovation Management, 27(1), 33-48.

Boyle, B. A., \& Magnusson, P. (2007). Social identity and brand equity formation: A comparative study of collegiate sports fans. Journal of Sport Management, 21(4), 497-520.

Braun, K. A., Ellis, R., \& Loftus, E. F. (2002). Make my memory: How advertising can change our memories of the past. Psychology \& Marketing, 19(1), 1-23.

Braun-LaTour, K. A., LaTour, M. S., \& Zinkhan, G. M. (2007). Using childhood memories to gain insight into brand meaning. Journal of Marketing, 71(2), 45-60.

Brexendorf, T. O., Bayus, B., \& Keller, K. L. (2015). Understanding the interplay between brand and innovation management: Findings and future research directions. Journal of the Academy of Marketing Science, 43(5), 548-557.

Brown, S., Kozinets, R. V., \& Sherry, J. F., Jr. (2003). Teaching old brands new tricks: Retro branding and the revival of brand meaning. Journal of Marketing, 67(3), 19-33.

Castaño, R., Sujan, M., Kacker, M., \& Sujan, H. (2008). Managing consumer uncertainty in the adoption of new products: Temporal distance and mental simulation. Journal of Marketing Research, 45(3), 320-336.

Cavusgil, S. T., Deligonul, S., Kardes, I., \& Cavusgil, E. (2018). Middleclass consumers in emerging markets: Conceptualization, propositions, and implications for international marketers. Journal of International Marketing, 26(3), 94-108.

Chatzipanagiotou, K., Veloutsou, C., \& Christodoulides, G. (2016). Decoding the complexity of the consumer-based brand equity process. Journal of Business Research, 69(11), 5479-5486.

Chen, F. F. (2007). Sensitivity of goodness of fit indexes to lack of measurement invariance. Structural Equation Modeling: A Multidisciplinary Journal, 14(3), 464-504. 
Cheung, G. W., \& Rensvold, R. B. (2002). Evaluating goodness-of-fit indexes for testing measurement invariance. Structural Equation Modeling: A Multidisciplinary Journal, 9(2), 233-255.

Choi, H., Ko, E., Kim, E. Y., \& Mattila, P. (2015). The role of fashion brand authenticity in product management: A holistic marketing approach. Journal of Product Innovation Management, 32(2), 233-242.

Clode, J. (2011). Marketers play on nostalgia to reach China's post-1980s generation. AdAge, 16 February. Retrieved June 6, 2018 from http:// adage.com/print/148906.

Coulter, R. A., Price, L. L., \& Feick, L. (2003). Rethinking the origins of involvement and brand commitment: Insights from postsocialist Central Europe. Journal of Consumer Research, 30(2), 151-169.

Diamantopoulos, A., Sarstedt, M., Fuchs, C., Wilczynski, P., \& Kaiser, S. (2012). Guidelines for choosing between multi-item and single-item scales for construct measurement: A predictive validity perspective. Journal of the Academy of Marketing Science, 40(3), 434-449.

Dimitriadou, M., Macjejovsky, B., Wildshut, T., \& Sedikides, C. (2015). Nostalgia and ethnocentric product preferences. Unpublished manuscript, Imperial College London.

Ding, Y., \& Keh, H. T. (2017). Consumer reliance on intangible versus tangible attributes in service evaluation: The role of construal level. Journal of the Academy of Marketing Science, 45(6), 848-865.

Eisend, M., Hartmann, P., \& Apaolaza, V. (2017). Who buys counterfeit luxury brands? A meta-analytic synthesis of consumers in developing and developed markets. Journal of International Marketing, 25(4), 89-111.

Euromonitor. (2012). Global nostalgia marketing. Executive briefing. In 31 August.

Ford, J. B., Merchant, A., Bartier, A.-L., \& Friedman, M. (2018). The cross-cultural scale development process: The case of brand-evoked nostalgia in Belgium and the United States. Journal of Business Research, 83, 19-29.

Fornell, C., \& Larcker, D. F. (1981). Evaluating structural equation models with unobservable variables and measurement error. Journal of Marketing Research, 18(1), 39-50.

Foucart, R., Wan, C., \& Wang, S. (2018). Innovations and technological comebacks. International Journal of Research in Marketing, 35(1), $1-14$.

Fournier, S. (1998). Consumers and their brands: Developing relationship theory in consumer research. Journal of Consumer Research, 24(4), 343-373

Fournier, S., \& Yao, J. L. (1997). Reviving brand loyalty: A reconceptualization within the framework of consumer-brand relationships. International Journal of Research in Marketing, 14(5), 451-472.

Friedman, L. (2016). Why nostalgia marketing works so well with millennials, and how your brand can profit. Forbes Retrieved June 8, 2018 from https://www.forbes.com/sites/laurenfriedman/2016/08/ 02/why-nostalgia-marketing-works-so-well-with-millennials-andhow-your-brand-can-benefit/\#20cb02583636/.

Fritz, K., Schoenmueller, V., \& Bruhn, M. (2017). Authenticity in branding: Exploring antecedents and consequences of brand authenticity. European Journal of Marketing, 51(2), 324-348.

Gao, H., Tate, M., Zhang, H., Chen, S., \& Liang, B. (2018). Social media ties strategy in international branding: An application of resourcebased theory. Journal of International Marketing, 26(3), 45-69.

Gineikiene, J., \& Diamantopoulos, A. (2017). I hate where it comes from but I still buy it: Countervailing influences of animosity and nostalgia. Journal of International Business Studies, 48(8), 992-1008.

Glen, J., Lee, K., \& Singh, A. (2003). Corporate profitability and the dynamics of competition in emerging markets: A time series analysis. The Economic Journal, 113(491), 465-484.

Greene, L. (2009). Adult nostalgia for childhood brands. Financial Times. Retrieved June 8, 2018 from https://www.ft.com/content/5a33e264f970-11dd-90c1-000077b07658
Grisaffe, D. B., \& Nguyen, H. P. (2011). Antecedents of emotional attachment to brands. Journal of Business Research, 64(10), 10521059 .

Gürhan-Canli, Z., Sarıl-Abi, G., \& Hayran, C. (2018). Consumers and brands across the globe: Research synthesis and new directions. Journal of International Marketing, 26(1), 96-117.

Hair, J. F., Black, W. C., Babin, B. J., \& Anderson, R. E. (2009). Multivariate data analysis (7th ed.). Upper Saddle River: Pearson.

Harvey, M. G., \& Griffith, D. A. (2007). The role of globalization, time acceleration, and virtual global teams in fostering successful global product launches. Journal of Product Innovation Management, 24(5), 486-501.

Hayes, A. F. (2013). Introduction to mediation, moderation, and conditional process analysis: A regression-based approach. New York: Guilford Press.

Heinberg, M., Ozkaya, H. E., \& Taube, M. (2016). A brand built on sand: Is acquiring a local brand in an emerging market an ill-advised strategy for foreign companies? Journal of the Academy of Marketing Science, 44(5), 586-607.

Heinberg, M., Ozkaya, H. E., \& Taube, M. (2017). The influence of global and local iconic brand positioning on advertising persuasion in an emerging market setting. Journal of International Business Studies, 48(8), 1009-1022.

Hepper, E. G., Wildschut, T., Sedikides, C., Ritchie, T. D., Yung, Y. F., Hansen, N., et al. (2014). Pancultural nostalgia: prototypical conceptions across cultures. Emotion, 14(4), 733-747.

Hofer, J. (1934). Medical dissertation on nostalgia (C. K. Anspach, trans.). Bulletin of the History of Medicine, 2, 376-391.

Hofstede, G., \& Minkov, M. (2010). Long- versus short-term orientation: New perspectives. Asia Pacific Business Review, 16(4), 493-504.

Holak, S. L., Matveev, A. V., \& Havlena, W. J. (2007). Nostalgia in postsocialist Russia: Exploring applications to advertising strategy. Journal of Business Research, 60(6), 649-655.

Holbrook, M. B. (1993). Nostalgia and consumption preferences: Some emerging patterns of consumer tastes. Journal of Consumer Research, 20(2), 245-256.

Hox, J. J. (2010). Multilevel analysis: Techniques and applications. New York: Taylor \& Francis.

Hult, G. T. M., Ketchen, D. J., Griffith, D. A., Finnegan, C. A., GonzalezPadron, T., \& Harmancioglu, N. (2008). Data equivalence in crosscultural international business research: Assessment and guidelines. Journal of International Business Studies, 39(6), 1027-1044.

Hung, K. H., Gu, F. F., \& Yim, C. K. (2007). A social institutional approach to identifying generation cohorts in China with a comparison with American consumers. Journal of International Business Studies, 38(5), 836-853.

Katsikeas, C. S., Samiee, S., \& Theodosiou, M. (2006). Strategy fit and performance consequences of international marketing standardization. Strategic Management Journal, 27(9), 867-890.

Katsikeas, C. S., Morgan, N. A., Leonidou, L. C., \& Hult, G. T. M. (2016). Assessing performance outcomes in marketing. Journal of Marketing, 80(2), 1-20.

Keller, K. L. (1993). Conceptualizing, measuring, and managing customer-based brand equity. Journal of Marketing, 57(1), 1-22.

Kessous, A., Roux, E., \& Chandon, J.-L. (2015). Consumer-brand relationships: A contrast of nostalgic and non-nostalgic brands. Psychology \& Marketing, 32(2), 187-202.

Klein, J. G., Ettenson, R., \& Morris, M. D. (1998). The animosity model of foreign product purchase: An empirical test in the People's Republic of China. Journal of Marketing, 62(1), 89-100.

Lambert-Pandraud, R., \& Laurent, G. (2010). Why do older consumers buy older brands? The role of attachment and declining innovativeness. Journal of Marketing, 74(5), 104-121.

Lamey, L., Deleersnyder, B., Steenkamp, J.-B. E. M., \& Dekimpe, M. G. (2012). The effect of business-cycle fluctuations on private-label 
share: What has marketing conduct got to do with it? Journal of Marketing, 76(1), 1-19.

Lannes, B., \& Booker, M. (2013). Growing brands by understanding what Chinese shoppers really do, Bain \& Company. Retrieved April 11, 2018 from http://www.bain.com/publications/articles/ Growing-brands-by-understanding-what-Chinese-shoppers-reallydo.aspx.

Leigh, T. W., Peters, C., \& Shelton, J. (2006). The consumer quest for authenticity: The multiplicity of meanings within the MG subculture of consumption. Journal of the Academy of Marketing Science, 34(4), 481-493.

Liberman, N., \& Trope, Y. (2008). The psychology of transcending the here and now. Science, 322(5905), 1201-1205.

Lin, H.-C., \& Kalwani, M. U. (2018). Culturally contingent electronic word-of-mouth signaling and screening: A comparative study of product reviews in the United States and Japan. Journal of International Marketing, 26(2), 80-102.

Liu, S., Perry, P., Moore, C., \& Warnaby, G. (2016). The standardizationlocalization dilemma of brand communications for luxury fashion retailers' internationalization into China. Journal of Business Research, 69(1), 357-364.

Loveland, K. E., Smeesters, D., \& Mandel, N. (2010). Still preoccupied with 1995: The need to belong and preference for nostalgic products. Journal of Consumer Research, 37(3), 393-408.

Malär, L., Krohmer, H., Hoyer, W. D., \& Nyffenegger, B. (2011). Emotional brand attachment and brand personality: The relative importance of the actual and the ideal self. Journal of Marketing, $75(4), 35-52$.

Moleskine (2018). The legendary notebook. Retrieved April 4, 2018 from $\mathrm{http}: / /$ www.moleskine.com/moleskine-world

Muehling, D. D., \& Sprott, D. E. (2004). The power of reflection: An empirical examination of nostalgia advertising effects. Journal of Advertising, 33(3), 25-35.

Muehling, D. D., Sprott, D. E., \& Sultan, A. J. (2014). Exploring the boundaries of nostalgic advertising effects: A consideration of childhood brand exposure and attachment on consumers' responses to nostalgia-themed advertisements. Journal of Advertising, 43(1), 7384.

Muthén, B. O. (2015). Mediation in two-level using bootstrap. Retrieved April 11, 2018 from http://www.statmodel.com/ discussion/ messages/12/20617.html?1482093468.

Muthén, L. K., \& Muthén, B. O. (2017). Mplus user's guide (8th ed.). Los Angeles: Muthén \& Muthén.

Napoli, J., Dickinson, S. J., Beverland, M. B., \& Farrelly, F. (2014). Measuring consumer-based brand authenticity. Journal of Business Research, 67(6), 1090-1098.

Nielsen (2013). Ad spend by sector: consumer goods marketers spend big. Retrieved January 10, 2019 from https://www.nielsen.com/ca/ en/insights/news/2013/ad-spend-by-sector-consumer-goodsmarketers-spend-bigger.print.html.

Ozkaya, E. H., Dabas, C., Kolev, K., Hult, G. T. M., Dahlquist, S. H., \& Manjeshwar, S. A. (2013). An assessment of hierarchical linear modeling in international business, management, and marketing. International Business Review, 22, 663-677.

Özsomer, A. (2012). The interplay between global and local brands: A closer look at perceived brand globalness and local iconness. Journal of International Marketing, 20(2), 72-95.

Park, C. S., \& Srinivasan, V. (1994). A survey-based method for measuring and understanding brand equity and its extendibility. Journal of Marketing Research, 31(2), 271-288.

Park, C. W., MacInnis, D. J., Priester, J., Eisingerich, A. B., \& Iacobucci, D. (2010). Brand attachment and brand attitude strength: Conceptual and empirical differentiation of two critical brand equity drivers. Journal of Marketing, 74(6), 1-17.
Parkinson, C., Liu, S., \& Wheatley, T. (2014). A common cortical metric for spatial, temporal, and social distance. The Journal of Neuroscience, 34(5), 1979-1987.

Pecot, F., Merchant, A., Valette-Florence, P., \& De Barnier, V. (2018). Cognitive outcomes of brand heritage: A signaling perspective. Journal of Business Research, 85, 304-316.

Pieters, R. G. M., \& Bijmolt, T. H. A. (1997). Consumer memory for television advertising: A field study of duration, serial position, and competition effects. Journal of Consumer Research, 23(4), 362-372.

Podsakoff, P. M., MacKenzie, S. B., Lee, J. Y., \& Podsakoff, N. P. (2003). Common method biases in behavioral research: A critical review of the literature and recommended remedies. Journal of Applied Psychology, 88(5), 879-903.

Raudenbush, S. W., \& Bryk, A. S. (2002). Hierarchical linear models: Applications and data analysis methods (2nd ed.). Thousand Oaks: Sage Publications.

Rego, L. L., Billett, M. T., \& Morgan, N. A. (2009). Consumer-based brand equity and firm risk. Journal of Marketing, 73(6), 47-60.

Roehm, M. L., \& Roehm, H. A., Jr. (2011). The influence of redemption time frame on responses to incentives. Journal of the Academy of Marketing Science, 39(3), 363-375.

Rogers, E. M. (2010). Diffusion of innovations. New York: The Free Press.

Rose, G. M., Merchant, A., Orth, U. R., \& Horstmann, F. (2016). Emphasizing brand heritage: Does it work? And how? Journal of Business Research, 69(2), 936-943.

Rubera, G. (2015). Design innovativeness and product sales' evolution. Marketing Science, 34(1), 98-115.

Schindler, R. M., \& Holbrook, M. B. (2003). Nostalgia for early experience as a determinant of consumer preferences. Psychology \& Marketing, 20(4), 275-302.

Sharma, P. (2011). Country of origin effects in developed and emerging markets: Exploring the contrasting roles of materialism and value consciousness. Journal of International Business Studies, 42(2), 285-306.

Sheth, J. N. (2011). Impact of emerging markets on marketing: Rethinking existing perspectives and practices. Journal of Marketing, 75(4), 166-182.

Shields, A. B., \& Johnson, J. W. (2016). What did you do to my brand? The moderating effect of brand nostalgia on consumer responses to changes in a brand. Psychology \& Marketing, 33(9), 713-728.

Smit, E., Bronner, F., \& Tolboom, M. (2007). Brand relationship quality and its value for personal contact. Journal of Business Research, 60(6), 627-633.

Sorescu, A. B., \& Spanjol, J. (2008). Innovation's effect on firm value and risk: Insights from consumer packaged goods. Journal of Marketing, 72(2), 114-132.

Spence, E. (2018). Nokia smartphone sales set to smash through ten million barrier. Forbes. Retrieved June 8, 2018 from https://www. forbes.com/sites/ewanspence/2018/02/04/hmdglobal-nokia-salestenmillion-mwc/\#18b1fd7b58c5.

Steenkamp, J.-B. E. M., \& Baumgartner, H. (1998). Assessing measurement invariance in cross-national consumer research. Journal of Consumer Research, 25(1), 78-90.

Steenkamp, J.-B. E. M., \& de Jong, M. G. (2010). A global investigation into the constellation of consumer attitudes toward global and local products. Journal of Marketing, 74(6), 18-40.

Steenkamp, J.-B. E. M., Hofstede, F. T., \& Wedel, M. (1999). A crossnational investigation into the individual and national cultural antecedents of consumer innovativeness. Journal of Marketing, 63(2), $55-69$.

Steenkamp, J.-B. E. M., Batra, R., \& Alden, D. L. (2003). How perceived brand globalness creates brand value. Journal of International Business Studies, 34(1), 53-65.

Stephan, E., Sedikides, C., \& Wildschut, T. (2012). Mental travel into the past: Differentiating recollections of nostalgic, ordinary, and positive events. European Journal of Social Psychology, 42(3), 290-298. 
The Economist (2014). Chinese consumers doing it their way: The market is growing furiously, but getting tougher for foreign firms, 25 January. Retrieved April 6, 2014 from www.economist.com/news/ briefing/21595019-market-growing-furiously-getting-tougherforeign-firms-doing-it-their-way.

Thelen, S., Ford, J. B., \& Honeycutt, E. D. (2006). The impact of regional affiliation on consumer perceptions of relationships among behavioral constructs. Journal of Business Research, 59(9), 965-973.

Thomson, M., MacInnis, D. J., \& Park, C. W. (2005). The ties that bind: Measuring the strength of consumers' emotional attachments to brands. Journal of Consumer Psychology, 15(1), 77-91.

Trope, Y., \& Liberman, N. (2010). Construal-level theory of psychological distance. Psychological Review, 117(2), 440-463.

Trope, Y., Liberman, N., \& Wakslak, C. (2007). Construal levels and psychological distance: Effects on representation, prediction, evaluation, and behaviour. Journal of Consumer Psychology, 17(2), 83-95.
Wildschut, T., Sedikides, C., Arndt, J., \& Routledge, C. (2006). Nostalgia: Content, triggers, functions. Journal of Personality and Social Psychology, 91(5), 975-993.

Wildschut, T., Sedikides, C., Routledge, C., Arndt, J., \& Cordaro, F. (2010). Nostalgia as a repository of social connectedness: The role of attachment-related avoidance. Journal of Personality and Social Psychology, 98(4), 573-586.

Yoo, B., Donthu, N., \& Lee, S. (2000). An examination of selected marketing mix elements and brand equity. Journal of the Academy of Marketing Science, 28(2), 195-211.

Zhou, L., Yang, Z., \& Hui, M. K. (2010). Non-local or local brands? A multi-level investigation into confidence in brand origin identification and its strategic implications. Journal of the Academy of Marketing Science, 38(2), 202-218.

Ziamou, P., \& Veryzer, R. W. (2005). The influence of temporal distance on consumer preferences for technology-based innovations. Journal of Product Innovation Management, 22(4), 336-346. 